\title{
Dynamic Modeling of Carnobacterium maltaromaticum CNCM I-3298 Growth and Metabolite Production and Model-Based Process Optimization
}

\author{
Cristian Puentes ${ }^{1,2}$, Amélie Girardeau ${ }^{1}$, Stephanie Passot ${ }^{1}$, Fernanda Fonseca ${ }^{1}$ and Ioan-Cristian Trelea ${ }^{1, *(1)}$ \\ 1 INRAE, AgroParisTech, UMR SayFood, Université Paris-Saclay, F-78850 Thiverval-Grignon, France; \\ cristian.puentes@centralesupelec.fr (C.P.); amelie.girardeau@inrae.fr (A.G.); stephanie.passot@inrae.fr (S.P.); \\ fernanda.fonseca@inrae.fr (F.F.) \\ 2 CentraleSupélec, LGPM, Université Paris-Saclay, F-91192 Gif-sur-Yvette, France \\ * Correspondence: ioan-cristian.trelea@inrae.fr; Tel.: +33-13-081-5490
}

check for updates

Citation: Puentes, C.; Girardeau, A.; Passot, S.; Fonseca, F.; Trelea, I.-C. Dynamic Modeling of Carnobacterium maltaromaticum CNCM I-3298 Growth and Metabolite Production and Model-Based Process Optimization. Foods 2021, 10, 1922. https:/ / doi.org/ 10.3390 /foods10081922

Academic Editor: Ursula Andrea Gonzales-Barron

Received: 16 July 2021

Accepted: 17 August 2021

Published: 19 August 2021

Publisher's Note: MDPI stays neutral with regard to jurisdictional claims in published maps and institutional affiliations.

Copyright: (c) 2021 by the authors. Licensee MDPI, Basel, Switzerland. This article is an open access article distributed under the terms and conditions of the Creative Commons Attribution (CC BY) license (https:// creativecommons.org/licenses/by/ $4.0 /)$

\begin{abstract}
Carnobacterium maltaromaticum is a species of lactic acid bacteria found in dairy, meat, and fish, with technological properties useful in food biopreservation and flavor development. In more recent years, it has also proven to be a key element of biological time-temperature integrators for tracking temperature variations experienced by perishable foods along the cold-chain. A dynamic model for the growth of C. maltaromaticum CNCM I-3298 and production of four metabolites (formic acid, acetic acid, lactic acid, and ethanol) from trehalose in batch culture was developed using the reaction scheme formalism. The dependence of the specific growth and production rates as well as the product inhibition parameters on the operating conditions were described by the response surface method. The parameters of the model were calibrated from eight experiments, covering a broad spectrum of culture conditions (temperatures between 20 and $37^{\circ} \mathrm{C}$; pH between 6.0 and 9.5). The model was validated against another set of eight independent experiments performed under different conditions selected in the same range. The model correctly predicted the growth kinetics of C. maltaromaticum CNCM I-3298 as well as the dynamics of the carbon source conversion, with a mean relative error of $10 \%$ for biomass and $14 \%$ for trehalose and the metabolites. The paper illustrates that the proposed model is a valuable tool for optimizing the culture of C. maltaromaticum CNCM I-3298 by determining operating conditions that favor the production of biomass or selected metabolites. Model-based optimization may thus reduce the number of experiments and substantially speed up the process development, with potential applications in food technology for producing starters and improving the yield and productivity of the fermentation of sugars into metabolites of industrial interest.
\end{abstract}

Keywords: Carnobacterium maltaromaticum; modeling; microbial growth; optimization; fermentation

\section{Introduction}

Carnobacterium maltaromaticum is a psychotropic species of lactic acid bacteria widely found in food such as dairy products, fish, and meat. It is a Gram-positive, facultative anaerobic bacterium, able to grow at alkaline $\mathrm{pH}$ (up to 9.6) [1,2].

In the food industry, C. maltaromaticum has potential applications related to health protection and organoleptic properties. These include the biopreservation of food, by inhibiting the growth of foodborne pathogens such as Listeria sp. in cold conditions, and the development of flavor in ripened cheese varieties [2-4].

This lactic acid bacterium may also be used as a biological indicator in time-temperature integrators (TTI): 'smart-labels' that monitor the time-temperature history of chilled products throughout the cold-chain [5,6]. Concentrates of the strain CNCM I-3298 have been selected as inoculum for TopCryo ${ }^{\circledR}$ labels, the only biological TTI that has been taken to market to date. A pH decline of the label medium, associated with bacterial growth and 
acid production, produces an irreversible color change from green to red as an indication to the consumer about the spoilage of the food to which the TTI is attached [7].

In these applications, C. maltaromaticum concentrates produced by fermentation may be used alone or in association with other microorganisms. Some experimental studies on C. maltaromaticum fermentation under different culture conditions have been reported in the literature $[3,4,6-14]$. The effect of temperature and $\mathrm{pH}$ on the acidifying activity was evaluated and modelled by Girardeau et al. [7]. However, there is a lack of knowledge on the characterization and optimization of Carnobacteria growth and production of various metabolites such as acids or flavor compounds in a bioreactor.

Carnobacteria are considered to be homofermentative lactic acid bacteria that produce lactic acid from glucose, with pyruvate as a central metabolic intermediate (via the EmbdenMeyerhof pathway) [15-17]. However, pyruvate may be alternatively converted to acetate, ethanol, formate, and $\mathrm{CO}_{2}[16,18]$ under anaerobic conditions and substrate limitation [19], arising for example at the end of fermentation [20]. The production of organic acids by Carnobacteria is also strain-dependent $[8,16,21]$. A recent study reported that lactic, formic, and acetic acids are key organic acids produced by C. maltaromaticum in a meat juice medium [22], indicating that this microorganism has the enzymatic machinery to perform mixed-acid fermentation (Figure 1).

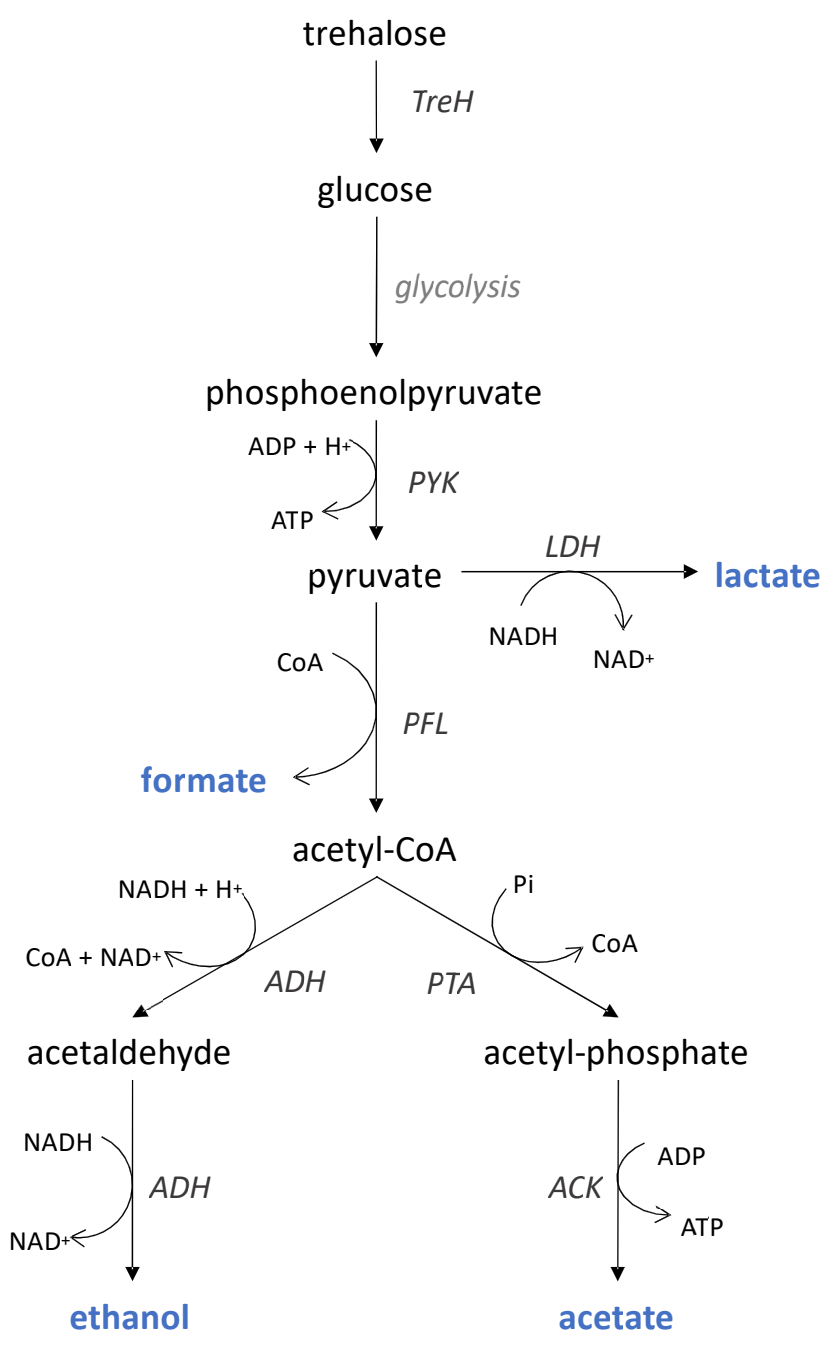

Figure 1. Mixed-acid fermentation pathway likely used by C. maltaromaticum to ferment trehalose. End products are shown in blue. ACK, acetate kinase; ADH, acetaldehyde dehydrogenase; LDH, lactate dehydrogenase; PFL, pyruvate formate lyase; PTA, phosphate acetyltransferase; PYK, pyruvate kinase; TreH, neutral trehalose. Adapted from [19-23]. 
For optimization purposes, modeling has proven to be a powerful tool, enabling the exploration of a wider range of operating conditions while minimizing cost, compared with the experimental approach [24-29]. To our knowledge, the only dynamic model dealing with C. maltaromaticum strains has been published by Ellouze et al. [6]. That research was oriented towards a biological TTI setting associated with a sausage-like packaging instead of a bioreactor and taking into account lactic acid as the single metabolite.

The aim of this study was thus to develop and validate a dynamic model predicting the impact of fermentation conditions (temperature and $\mathrm{pH}$ ) on the growth and bioconversion fermentation dynamics of $C$. maltaromaticum CNCM I-3298 using trehalose as a carbon source and considering the four main identified metabolites: formic acid, acetic acid, lactic acid, and ethanol. This study was conducted as part of a research project on the production and conservation of $C$. maltaromaticum concentrates. In that context, the growth of $C$. maltaromaticum was tested in different sugars: glucose, maltose, mannitol, and trehalose, with similar growth rates. Trehalose was chosen in this study because this molecule is known for its ability to protect cells during bacterial stabilization processes (freeze-drying in particular). Therefore, the residual trehalose (not consumed during fermentation) could be used as cryoprotectant after production of bacterial concentrates.

The model development involved four major steps, presented in Section 3: derivation of the main governing equations based on the known mixed-acid fermentation pathway, mass balances, and kinetic rate expressions (Section 3.1); parameter identification for each fermentation experiment (Section 3.2); construction of response surfaces of the calibrated parameters as a function of temperature and $\mathrm{pH}$ (Section 3.3); and final validation of the complete model. The resulting model is shown to be a useful tool in determining the optimal conditions for producing bacterium concentrates in bioreactors and for assessing the productivity of the bioconversion fermentation of sugars into metabolites of potential industrial interest (Section 4.4).

\section{Materials and Methods}

Data used to calibrate and validate the model were partially reported in a previous study, in which a modified central composite experimental design was carried out to study the effect of operating conditions on the technological properties of C. maltaromaticum CNCM I-3298 [7]. Sixteen lab-scale fermentations (hereafter named F01 to F16) were performed using a wide range of regulated operating conditions (Figure 2): temperature between 20 and $37^{\circ} \mathrm{C}$ and $\mathrm{pH}$ between 6.0 and 9.5.

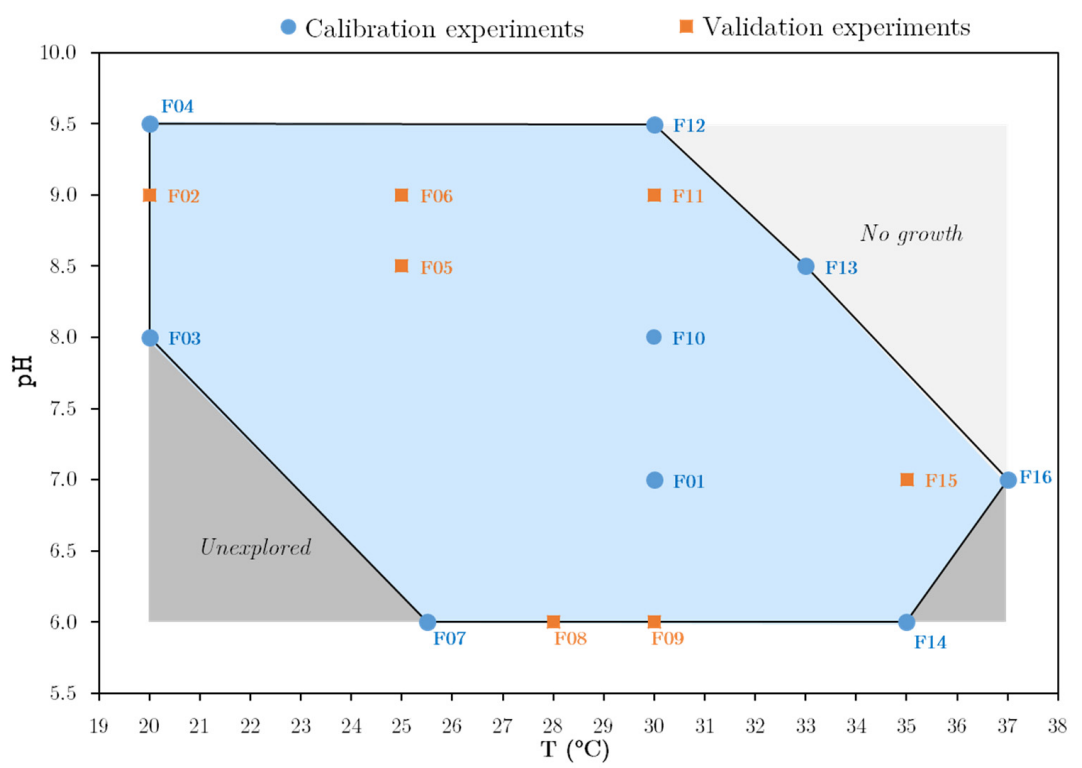

Figure 2. Operating conditions of C. maltaromaticum CNCM I-3298 fermentation experiments. 
Fermentation durations varied between $20 \mathrm{~h}$ and $45 \mathrm{~h}$, and the initial conditions were: for biomass $\left(X_{0}\right) 0.077 \mathrm{~mol}_{\mathrm{C}} \cdot \mathrm{L}^{-1}$, trehalose $\left(\mathrm{S}_{0}\right)$ between $0.091 \mathrm{~mol} \cdot \mathrm{L}^{-1}$ and $0.107 \mathrm{~mol} \cdot \mathrm{L}^{-1}$, and medium volume $\left(\mathrm{V}_{0}\right) 3.5 \mathrm{~L}$.

The main fermentation settings and the kinetic measurements are reported below.

\subsection{Fermentation}

\subsubsection{Culture Medium and Bacterial Strain}

The fermentation medium was composed of the following ingredients for $1 \mathrm{~kg}$ of final solution: $40 \mathrm{~g}$ of trehalose (Treha ${ }^{\mathrm{TM}}$; Tokyo Japan); $10 \mathrm{~g}$ of proteose peptone (Oxoid; Waltham, MA, USA); $5 \mathrm{~g}$ of yeast extract (Humeau; La-Chapelle-sur-Erdre, France); $5 \mathrm{~g}$ of Tween 80 (VWR; Leuven, Belgium); $0.41 \mathrm{~g}$ of $\mathrm{MgSO}_{4}$ (Merck; Darmstadt, Germany); $0.056 \mathrm{~g} \mathrm{MnSO}_{4}$ (Merck; Darmstadt, Germany); and water to reach a total of $1 \mathrm{~kg}$ of solution. All medium components were sterilized together at $121^{\circ} \mathrm{C}$ for $20 \mathrm{~min}$. Fermentations were carried out on C. maltaromaticum CNCM I-3298 pre-cultures. Pre-cultures were prepared by inoculating $10 \mathrm{~mL}$ of sterilized fermentation medium with $100 \mu \mathrm{L}$ of $\mathrm{C}$. maltaromaticum CNCM I-3298 stock culture and were incubated for 13 to $16 \mathrm{~h}$ at $30^{\circ} \mathrm{C}$. An amount of $1 \mathrm{~mL}$ of the resulting culture was transferred into $50 \mathrm{~mL}$ of fresh medium and then incubated again for $11 \mathrm{~h}$ under the same conditions. The resulting culture was then used to inoculate the bioreactor. Inoculation was performed at an initial concentration of approximately $10^{7} \mathrm{CFU} \mathrm{mL}^{-1}$.

\subsubsection{Bioreactor and Parameter Control}

The bioreactor (Minifors, Infors HT, Bottmingen, Switzerland) had a total volume of $5 \mathrm{~L}$ and was equipped with a heat mantle and a cryostat for temperature control. It contained 3.5 L of fermentation medium, inoculated with an initial cell concentration of approximately $10^{7} \mathrm{CFU} \cdot \mathrm{mL}^{-1}$. Initial $\mathrm{pH}$ was adjusted to the desired value with $5 \mathrm{M} \mathrm{NaOH}$ or $0.01 \mathrm{M} \mathrm{H}_{2} \mathrm{SO}_{4}$ solutions. During fermentation, $\mathrm{pH}$ was controlled to the desired setpoint for each investigated condition (Figure 2) by automatic addition of $5 \mathrm{M} \mathrm{NaOH}$. Culture homogenization was performed with an agitation device set at $150 \mathrm{rpm}$. Temperature was set according to the investigated operating conditions mentioned above (Figure 2).

\subsection{Kinetic Measurements \\ 2.2.1. Cell Growth}

Cell growth was monitored using an infrared probe (Excell210, CellD, Roquemaure, France) continuously measuring absorbance at $880 \mathrm{~nm}$ and storing data every minute. The absorbance data were calibrated in dry weight. Dry cell weight was determined by filtering $10 \mathrm{~mL}$ of bacterial suspension (straight out of the bioreactor) through a $0.20 \mu \mathrm{m}$ polyethersulfone membrane (Supor ${ }^{\circledR}$, PALL Biotech, Saint-Germain-en-Laye, France). The filter was then dried for $24 \mathrm{~h}$ at $80{ }^{\circ} \mathrm{C}$. Measurements were obtained in triplicate. Mass concentrations were finally converted to $\mathrm{mol}_{\mathrm{C}} \mathrm{L}^{-1}$ (carbon-mol of biomass per liter), assuming the simplified unit-carbon biomass formula $\mathrm{CH}_{1.8} \mathrm{O}_{0.5}$ [30].

\subsubsection{Total Acid Production}

Total acid production was determined according to the volume of $\mathrm{NaOH}$ solution injected into the bioreactor to maintain a constant $\mathrm{pH}$. The $\mathrm{pH}$ was regulated/controlled to set values using the IRIS NT V5 software (Infors, AG, Bottmingen, Switzerland).

\subsubsection{Substrate Consumption and Metabolite Production}

Trehalose consumption and metabolite production were determined using highperformance liquid chromatography (HPLC, Waters Associates, Millipore; Molsheim, France). HPLC was performed on culture media samples of a few $\mathrm{mL}$, aseptically retrieved from the bioreactor at different times during fermentation and filtered through $0.22 \mu \mathrm{m}$ pores (Sartorius stedim, Biotech; Göttigen, Germany). Analyses were made using a cation exchange column (Aminex Ion Exclusion HPX-87 $300 \times 7.8$ mm, Bio-Rad, Richmond, VA, 
USA) at $35^{\circ} \mathrm{C}$. Mobile phase was $0.0005 \mathrm{M} \mathrm{H}_{2} \mathrm{SO}_{4}$, and flow rate was set at $0.6 \mathrm{~mL} \cdot \mathrm{min}^{-1}$ (LC-6A pump, Shimadzu, Courtaboeuf, France).

HPLC analysis showed that C. maltaromaticum CNCM I-3298 produced not only lactic acid but also formic acid, acetic acid, and ethanol in variable proportions according to the fermentation conditions.

\section{Dynamic Model}

The mathematical model was a set of ordinary differential equations implemented in MATLAB R2018b (the MathWorks Inc. Natick, MA, USA). Model parameters and response surface coefficients were identified by nonlinear regression analysis using the Statistic and Machine Learning Toolbox of MATLAB.

\subsection{Model Formulation}

The dynamic model developed in this study combined biochemical knowledge about the metabolism of the selected bacterium and mass balances of the main compounds: substrate, biomass, and identified metabolites. Expressions of specific growth and metabolite production rates included substrate limitation, product inhibition phenomena, and time lags due to microbial metabolism adaptation [31]. The surface response method was used to express the empiric dependence of some model parameters on operating conditions. The model assumed the bioreactor was perfectly stirred and there were no differences between individual cells. It was thus unsegregated and zero-dimensional, predicting average spatial concentrations [32].

Seven state variables were considered: six volume concentrations (biomass $[\mathrm{X}]$, trehalose [S], formic acid [F], acetic acid [A], lactic acid [L], and ethanol [E], Figure 1) and the culture medium volume $(\mathrm{V})$. This latter variable varied continuously with the addition of base $(\mathrm{NaOH})$ for $\mathrm{pH}$ control but also changed in a discrete way due to periodic sampling for biological and chemical analysis.

Mass balances for the considered metabolites resulted in the following set of differential equations:

$$
\begin{aligned}
& \frac{d[X]}{d t}=\mu_{X}[X]-\frac{Q}{V}[X] \\
& \frac{d[F]}{d t}=\pi_{F}[X]-\frac{Q}{V}[F] \\
& \frac{d[A]}{d t}=\pi_{A}[X]-\frac{Q}{V}[\mathrm{~A}] \\
& \frac{d[L]}{d t}=\pi_{L}[X]-\frac{Q}{V}[L] \\
& \frac{d[E]}{d t}=\pi_{E}[X]-\frac{Q}{V}[E] \\
& \frac{d\left[A_{T}\right]}{d t}=\frac{d[F]}{d t}+\frac{d[A]}{d t}+\frac{d[L]}{d t} \\
& \frac{d[S]}{d t}=-\left(\frac{\mu_{X}}{Y_{X / S}}+\frac{\pi_{F}}{Y_{F} / S}+\frac{\pi_{A}}{Y_{A} / S}+\frac{\pi_{L}}{Y_{L} / S}+\frac{\pi_{E}}{Y_{E} / S}\right)[X]-\frac{Q}{V}[S] \\
& \frac{d V}{d t}=Q
\end{aligned}
$$

Here, $\mu_{\mathrm{X}}$ is the specific growth rate $\left(\mathrm{h}^{-1}\right) ; \pi_{\mathrm{F}}, \pi_{\mathrm{A}}, \pi_{\mathrm{L}}$, and $\pi_{\mathrm{E}}$ are the specific production rates of four metabolites $\left(h^{-1}\right)$; and $Y_{X / S}, Y_{F / S}, Y_{A} / S, Y_{L / S}$, and $Y_{E / S}$ are the yield of

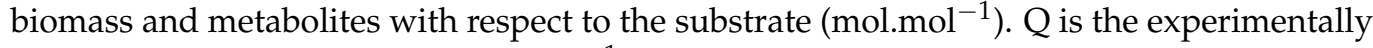

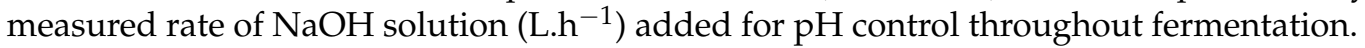

In Equation (6), $\left[\mathrm{A}_{\mathrm{T}}\right]$ is the total acid concentration, defined as the sum of formic, acetic, and lactic acid concentrations. These compounds are assumed to be mainly responsible for the $\mathrm{pH}$ change of the liquid medium. 
Specific growth and production rates were defined using the Monod law to account for substrate limitation, modified with product inhibition and enzymatic activation factors [33-35]:

$$
\begin{gathered}
\mu_{\mathrm{X}}=\mu_{\max , X} \mathrm{I}_{\mathrm{X}} \mathrm{E}_{\mathrm{A}} \frac{[\mathrm{S}]}{\mathrm{K}_{\mathrm{SX}}+[\mathrm{S}]} \\
\pi_{\mathrm{m}}=\pi_{\mathrm{max}, \mathrm{m}} \mathrm{I}_{\mathrm{m}} \mathrm{E}_{\mathrm{A}} \frac{[\mathrm{S}]}{\mathrm{K}_{\mathrm{Sm}}+[\mathrm{S}]} \quad \mathrm{m}=\mathrm{F}, \mathrm{A}, \mathrm{L}, \mathrm{E}
\end{gathered}
$$

In these equations, $\mathrm{I}_{\mathrm{x}}$ and $\mathrm{I}_{\mathrm{m}}$ are inhibition factors that depend on the inhibitor concentration. They vary between 1 and 0 . Inhibition increases with the inhibitor concentration, and its effect on the specific rate is maximal when the corresponding factor is 0 . In this model, progressive inhibition factors of the following form were used [36,37]:

$$
\begin{gathered}
\mathrm{IX}_{\mathrm{X}}=\frac{1}{1+\left(\frac{\mathrm{C}_{\mathrm{I}}}{\mathrm{K}_{\mathrm{IX}}}\right)^{n}} \\
\mathrm{I}_{\mathrm{m}}=\frac{1}{1+\left(\frac{\mathrm{C}_{\mathrm{I}}}{\mathrm{K}_{\mathrm{Im}}}\right)^{p}} \mathrm{~m}=\mathrm{F}, \mathrm{A}, \mathrm{L}, \mathrm{E}
\end{gathered}
$$

$\mathrm{K}_{\mathrm{IX}}$ and $\mathrm{K}_{\mathrm{Im}}$ represent characteristic concentrations of the inhibitors $\left(\mathrm{mol} \mathrm{L}^{-1}\right)$ such that the corresponding rates $\left(\mu_{\mathrm{X}}\right.$ and $\left.\pi_{\mathrm{m}}\right)$ are reduced by a factor of 2 compared with the absence of inhibitor, $n$ and $p$ are shape factors, and $C_{I}$ is the concentration of the inhibitor. Since all the metabolites were produced in similar proportions and no biochemical knowledge about their relative inhibiting nature was available, $C_{I}$ was simply defined as the sum of the four metabolite concentrations:

$$
\mathrm{C}_{\mathrm{I}}=[\mathrm{F}]+[\mathrm{A}]+[\mathrm{L}]+[\mathrm{E}]
$$

To illustrate the role of the shape factor n, Figure 3a depicts the evolution of $I_{X}$ with $C_{I}$ for different $\mathrm{n}$ values and a lag-time of $5 \mathrm{~h}$. A more or less sharp change in the inhibition factor occurs around the characteristic inhibitor concentration, $C_{I}=K_{I X}$. The significance of the shape factor $\mathrm{p}$ is similar.

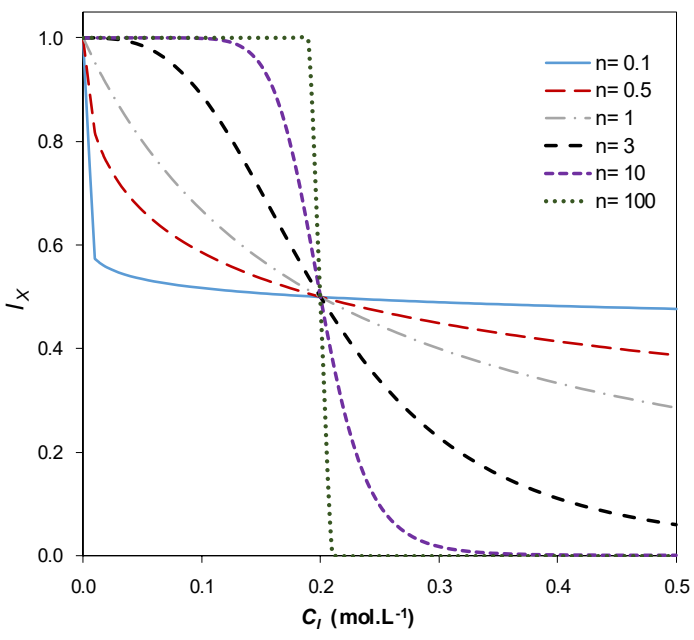

(a)

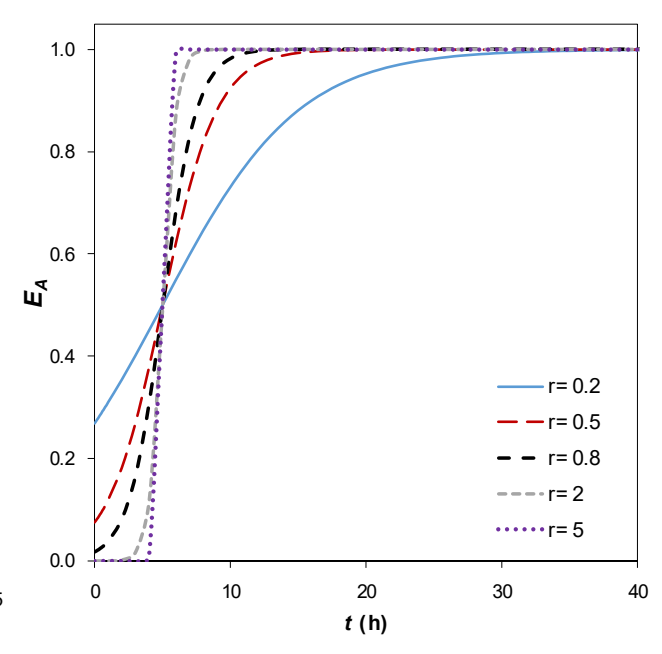

(b)

Figure 3. (a) Example of inhibition factor $\mathrm{I}_{X}$ as a function of $C_{I}$ for different $n$ values and $K_{I X}=0.2 \mathrm{~mol} \mathrm{~L}^{-1}$. (b) Example of enzymatic activation factor $E_{A}$ as a function of $t$ for different $r$ values, and $t_{\text {lag }}=5 \mathrm{~h}$. 
The enzymatic adaptation factor $\mathrm{E}_{\mathrm{A}}$ is an empirical representation of the lag time, $\mathrm{a}$ period of adaptation to the culture environment where the microorganism produces new enzymatic machinery [38-40]. Based on the shape of experimental data, the following equation was proposed:

$$
\mathrm{E}_{\mathrm{A}}=\frac{1}{1+\exp \left(-\mathrm{r}\left(\mathrm{t}-\mathrm{t}_{\mathrm{lag}}\right)\right)}
$$

where $t_{\text {lag }}(h)$ is the lag time experimentally observed. Figure $3 b$ shows that $E_{A}$ is an increasing function of time, tending to 1 when $t \gg t_{l a g}$. In analogy with $n, r$ is a shape factor that describes the gradual transition from the lag phase to the active phase of growth. A higher value of $r$ implies a steeper change of $E_{A}$ around $t=t_{l a g}$.

To illustrate the features of the proposed model, a representation of the dimensionless specific growth and production rates $\left(\mu / \mu_{\max }\right.$ and $\left.\pi / \pi_{\max }\right)$ over time is depicted in Figure 4 . The dynamic behavior of both variables is similar given the similarity of Equations (1)-(5). The specific rates achieve a maximum value in the active growth phase, and they are zero when $t \ll t_{\text {lag }}$ and when the substrate is depleted. The shape of the curve is defined by three factors: in the increasing region ( 0 to $10 \mathrm{~h}$ in Figure 4$)$, the dominant effect is enzyme activation $\mathrm{E}_{\mathrm{A}}$ (Equation (14)); in the slowly decreasing region (10 to $20 \mathrm{~h}$ ), the rate is controlled by inhibition (Equation (11) or (12)), whereas in the sharply decreasing region ( 20 to $22 \mathrm{~h}$ ) it is controlled by substrate limitation, corresponding to the Monod-like factor in Equation (9) or (10).

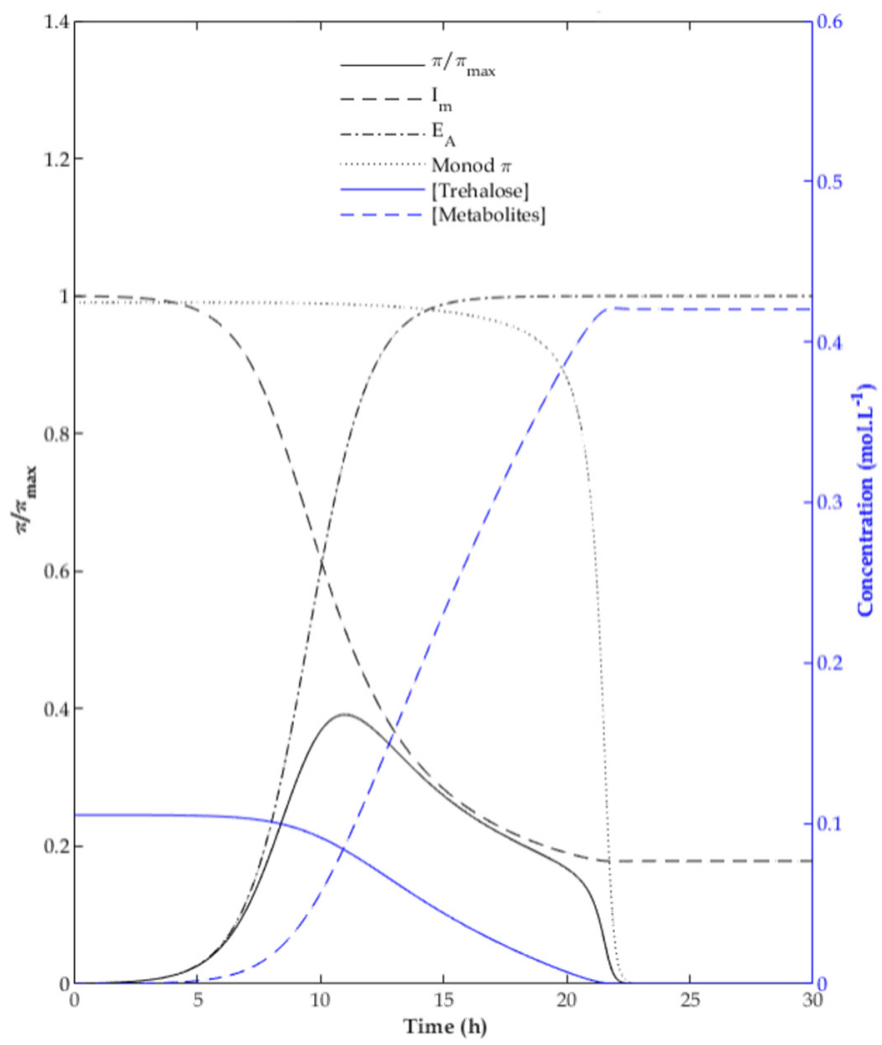

Figure 4. Typical evolution of the relative production rate over time.

\subsection{Model Parameter Identification}

The system of kinetic equations for a single fermentation experiment included 24 parameters: five yield coefficients, five inhibition parameters, five growth/production rates, five Monod-like saturation constants, three shape factors, and one lag time. Due to a limited number of experimental data and to facilitate the identification procedure, a single value was adopted for the inhibition parameter $\left(\mathrm{K}_{\mathrm{Im}}\right)$ and the Monod saturation constant $\left(\mathrm{K}_{\mathrm{Sm}}\right)$ of the four identified metabolites. Moreover, 10 parameters were fixed 
for all experiments: the shape factors, the yield coefficients, and the Monod saturation constants $\left(\mathrm{K}_{\mathrm{SX}}\right.$ and $\left.\mathrm{K}_{\mathrm{Sm}}\right)$. For each fermentation, lag time was determined by graphical readout. This simplification of fixing parameters independent of operating conditions is supported by two assumptions often used in the literature: (1) metabolite production yields are constant and therefore independent of culture conditions [41] and (2) the saturation constant of the Monod model depends only on the nature of the substrate $[33,38]$, which was the same in all experiments of this study.

The remaining group of seven parameters $\left(\mu_{\max , X}, \pi_{\max , \mathrm{F}}, \pi_{\max , \mathrm{A}}, \pi_{\max , \mathrm{L}}, \pi_{\max , \mathrm{E}}\right.$, $\mathrm{K}_{\mathrm{IX}}, \mathrm{K}_{\mathrm{Im}}$ ) were identified for each fermentation of the experimental design by nonlinear regression. Here, the Levenberg-Marquardt algorithm [42] was used to minimize the sum of squares of the errors between experimental and predicted concentrations. However, since the ranges and the number of measurements were slightly different among the metabolites, the values compared in the least squares function were normalized by dividing by their maximum value and were weighted by the relevant number of experimental measurements.

The quality of the model representation was quantified with two error indicators, defined as follows:

Root mean square error:

$$
\text { RMSE }=\left[\frac{1}{\mathrm{~N}} \sum_{\mathrm{i}=1}^{\mathrm{N}}\left(\mathrm{C}_{\text {model }, \mathrm{i}}-\mathrm{C}_{\text {exp }, \mathrm{i}}\right)^{2}\right]^{1 / 2}
$$

Relative mean error (as a percentage):

$$
\mathrm{RME}=\frac{1}{\mathrm{~N}} \sum_{\mathrm{i}=1}^{\mathrm{N}} \frac{\left|\mathrm{C}_{\text {model }, \mathrm{i}}-\mathrm{C}_{\text {exp }, \mathrm{i}}\right|}{\mathrm{C}_{\text {exp,max }}-\mathrm{C}_{\text {exp }, \min }} \cdot 100 \%
$$

where $\mathrm{N}$ is the number of available measurements, $\mathrm{C}_{\text {model }}$ and $\mathrm{C}_{\exp }$ are respectively the values of the concentration variables calculated with the model and measured experimentally.

\subsection{Response Surface Model for Parameter Dependence on Fermentation Conditions}

Nonlinear regression was performed to model the relationship between the seven parameters of the dynamic model specific to each experiment and the fermentation operating conditions-namely, temperature $(\mathrm{T})$ and $\mathrm{pH}$. The regression model had a similar form for all parameters, the logarithm of the parameter being expressed as a second-order polynomial with interaction:

$$
\log _{10} \operatorname{Par}_{i}=\beta_{0 \mathrm{i}}+\beta_{1 \mathrm{i}} \mathrm{T}+\beta_{2 \mathrm{i}} \mathrm{pH}+\beta_{3 \mathrm{i}} \mathrm{T}^{2}+\beta_{4 \mathrm{i}} \mathrm{pH}^{2}+\beta_{5 \mathrm{i}} \mathrm{TpH}
$$

The regression coefficients $(\beta)$ for all parameters depending on operating conditions $\left(\mu_{\max , X}, \pi_{\max , \mathrm{F}}, \pi_{\max , \mathrm{A}}, \pi_{\max , \mathrm{L}}, \pi_{\max , \mathrm{E}}, \mathrm{K}_{\mathrm{IX}}, \mathrm{K}_{\mathrm{Im}}\right)$ were simultaneously computed by leastsquares optimization based on all available concentration measurements. In this way, the accuracy and standard errors of the coefficients were statistically acceptable, due to a large number of degrees of freedom: several hundreds of concentration data were used to estimate 42 coefficients. Initial guesses for these coefficients were obtained using Equation (17), and parameter values were determined separately for each experiment.

In this procedure, two sets of data from the experimental design were defined as indicated in Figure 2: eight calibration experiments, located in extreme positions of the experimental domain, used simultaneously for coefficients $(\beta)$ estimation, and eight validation experiments, only used a posteriori to verify the accuracy of the complete dynamic model.

\section{Results and Discussion}

\subsection{Model Parameter Identification}

The values of the parameters that are independent of operating conditions, summarized in Table 1, were determined from the experimental data of experiment F10. This run 
was placed in a central position in the composite experimental design $\left(\mathrm{T}=30^{\circ} \mathrm{C}, \mathrm{pH}=8\right)$ (Figure 2). Monod saturation constants are usually difficult to determine from batch experiments because the number of measurements is typically very low in the substrate limitation zone. Saturation constants were thus fixed to a common value with a typical order of magnitude [43]. As for yields, they were found to differ from the theoretical ones defined through standard stoichiometric reactions of anabolism and catabolism. These differences can be due to other reactions involving the carbon substrate, whose products were not analytically measured and were not considered in the model.

Table 1. Model parameters independent of operating conditions, determined from the experimental data of experiment $\mathrm{F} 10\left(\mathrm{~T}=30^{\circ} \mathrm{C}, \mathrm{pH}=8\right)$ with $\mathrm{t}_{\text {lag }}=10 \mathrm{~h}$.

\begin{tabular}{cc}
\hline Parameter & Constant Value \\
\hline $\mathrm{Y}_{\mathrm{X} / \mathrm{S}}\left(\mathrm{mol}_{\mathrm{C}} \cdot \mathrm{mol}^{-1}\right)$ & 6.9 \\
$\mathrm{Y}_{\mathrm{F} / \mathrm{S}}\left(\mathrm{mol}_{\mathrm{mol}}^{-1}\right)$ & 5.6 \\
$\mathrm{Y}_{\mathrm{A} / \mathrm{S}}\left(\mathrm{mol}_{\mathrm{mol}}^{-1}\right)$ & 3.8 \\
$\mathrm{Y}_{\mathrm{L} / \mathrm{S}}\left(\mathrm{mol}_{\mathrm{mol}}^{-1}\right)$ & 7.0 \\
$\mathrm{Y}_{\mathrm{E} / \mathrm{S}}\left(\mathrm{mol}^{-1} \mathrm{~mol}^{-1}\right)$ & 4.7 \\
$\mathrm{~K}_{\mathrm{SX}}\left(\mathrm{mol} \mathrm{L}^{-1}\right)$ & 0.001 \\
$\mathrm{~K}_{\mathrm{Sm}}\left(\mathrm{mol} \mathrm{L}^{-1}\right)$ & 0.001 \\
$n$ & 3 \\
$p$ & 1 \\
$\mathrm{r}\left(\mathrm{h}^{-1}\right)$ & 0.8 \\
\hline
\end{tabular}

After fixing the parameters in Table 1 for the whole set of experiments, the group of seven adjustable parameters of the model $\left(\mu_{\max , X}, \pi_{\max , \mathrm{F}}, \pi_{\max , \mathrm{A}}, \pi_{\max , \mathrm{L}}, \pi_{\max , \mathrm{E}}, \mathrm{K}_{\mathrm{IX}}, \mathrm{K}_{\mathrm{Im}}\right)$ were identified for each run by nonlinear regression.

The parameters obtained by this procedure are summarized in Table 2. Standard errors were computed from the variance-covariance matrix of the nonlinear optimization algorithm. These errors represented between $5 \%$ and $13 \%$ of the value of the identified parameters, a reasonable uncertainty level for a biological model.

Table 2. Model parameters determined for each experiment by nonlinear regression.

\begin{tabular}{|c|c|c|c|c|c|c|c|c|}
\hline & Fermentation & $\begin{array}{c}\mu_{\max X} \\
\left(h^{-1}\right)\end{array}$ & $\begin{array}{c}\pi_{\operatorname{maxF}} \\
\left(\mathrm{h}^{-1}\right)\end{array}$ & $\begin{array}{c}\pi_{\operatorname{maxA}} \\
\left(\mathrm{h}^{-1}\right)\end{array}$ & $\begin{array}{c}\pi_{\operatorname{maxL}} \\
\left(\mathrm{h}^{-1}\right)\end{array}$ & $\begin{array}{c}\pi_{\operatorname{maxE}} \\
\left(\mathrm{h}^{-1}\right)\end{array}$ & $\begin{array}{c}\mathrm{KI}_{\mathbf{X}} \\
\left(\mathrm{Mol}^{-L^{-1}}\right)\end{array}$ & $\begin{array}{c}\mathrm{KI}_{\mathrm{m}} \\
\left(\mathrm{Mol}^{-1} \mathrm{~L}^{-1}\right)\end{array}$ \\
\hline \multirow{2}{*}{ F01 } & Value & 0.224 & 0.152 & 0.064 & 0.215 & 0.078 & 0.117 & 0.069 \\
\hline & Standard error & 0.003 & 0.003 & 0.003 & 0.005 & 0.001 & 0.004 & 0.003 \\
\hline \multirow{2}{*}{ F02 } & Value & 0.096 & 0.122 & 0.064 & 0.053 & 0.064 & 0.143 & 0.142 \\
\hline & Standard error & 0.021 & 0.012 & 0.007 & 0.006 & 0.006 & 0.083 & 0.036 \\
\hline \multirow{2}{*}{ F03 } & Value & 0.164 & 0.137 & 0.064 & 0.131 & 0.072 & 0.099 & 0.102 \\
\hline & Standard error & 0.012 & 0.009 & 0.004 & 0.009 & 0.005 & 0.006 & 0.013 \\
\hline \multirow{2}{*}{ F04 } & Value & 0.078 & 0.063 & 0.031 & 0.072 & 0.034 & 0.144 & 0.092 \\
\hline & Standard error & 0.012 & 0.004 & 0.002 & 0.004 & 0.002 & 0.047 & 0.016 \\
\hline \multirow{2}{*}{ F05 } & Value & 0.130 & 0.130 & 0.060 & 0.196 & 0.070 & 0.160 & 0.100 \\
\hline & Standard error & 0.005 & 0.002 & 0.002 & 0.004 & 0.001 & 0.004 & 0.004 \\
\hline \multirow{2}{*}{ F06 } & Value & 0.094 & 0.129 & 0.063 & 0.159 & 0.063 & 0.163 & 0.092 \\
\hline & Standard error & 0.001 & 0.002 & 0.001 & 0.003 & 0.001 & 0.003 & 0.002 \\
\hline \multirow{2}{*}{ F07 } & Value & 0.074 & 0.028 & 0.010 & 0.089 & 0.022 & 0.122 & 0.139 \\
\hline & Standard error & 0.002 & 0.001 & 0.001 & 0.004 & 0.002 & 0.005 & 0.004 \\
\hline \multirow{2}{*}{ F08 } & Value & 0.060 & 0.055 & 0.024 & 0.126 & 0.048 & 0.149 & 0.060 \\
\hline & Standard error & 0.002 & 0.002 & 0.000 & 0.003 & 0.002 & 0.001 & 0.002 \\
\hline \multirow{2}{*}{ F09 } & Value & 0.071 & 0.097 & 0.048 & 0.114 & 0.071 & 0.108 & 0.044 \\
\hline & Standard error & 0.009 & 0.007 & 0.004 & 0.010 & 0.006 & 0.021 & 0.007 \\
\hline
\end{tabular}


Table 2. Cont.

\begin{tabular}{|c|c|c|c|c|c|c|c|c|}
\hline & Fermentation & $\begin{array}{c}\mu_{\max X} \\
\left(h^{-1}\right)\end{array}$ & $\begin{array}{l}\pi_{\operatorname{maxF}} \\
\left(\mathrm{h}^{-1}\right)\end{array}$ & $\begin{array}{c}\pi_{\operatorname{maxA}} \\
\left(\mathrm{h}^{-1}\right)\end{array}$ & $\begin{array}{c}\pi_{\operatorname{maxL}} \\
\left(h^{-1}\right)\end{array}$ & $\begin{array}{c}\pi_{\operatorname{maxE}} \\
\left(h^{-1}\right)\end{array}$ & $\begin{array}{c}\mathrm{KI}_{\mathbf{X}} \\
\left({\left.\mathrm{Mol} . \mathrm{L}^{-1}\right)}^{-1}\right.\end{array}$ & $\begin{array}{c}\mathrm{KI}_{\mathrm{m}} \\
\left(\mathrm{Mol}^{-1} \mathrm{~L}^{-1}\right)\end{array}$ \\
\hline \multirow{2}{*}{ F10 } & Value & 0.220 & 0.230 & 0.100 & 0.300 & 0.120 & 0.193 & 0.091 \\
\hline & Standard error & 0.051 & 0.013 & 0.007 & 0.022 & 0.007 & 0.044 & 0.015 \\
\hline \multirow{2}{*}{ F11 } & Value & 0.121 & 0.127 & 0.060 & 0.116 & 0.066 & 0.179 & 0.133 \\
\hline & Standard error & 0.004 & 0.007 & 0.004 & 0.005 & 0.003 & 0.006 & 0.003 \\
\hline \multirow{2}{*}{ F12 } & Value & 0.132 & 0.155 & 0.082 & 0.076 & 0.086 & 0.043 & 0.059 \\
\hline & Standard error & 0.010 & 0.026 & 0.003 & 0.002 & 0.006 & 0.002 & 0.007 \\
\hline \multirow{2}{*}{ F13 } & Value & 0.147 & 0.162 & 0.077 & 0.219 & 0.092 & 0.164 & 0.106 \\
\hline & Standard error & 0.006 & 0.006 & 0.002 & 0.008 & 0.004 & 0.009 & 0.003 \\
\hline \multirow{2}{*}{ F14 } & Value & 0.047 & 0.045 & 0.020 & 0.112 & 0.032 & 0.140 & 0.130 \\
\hline & Standard error & 0.005 & 0.004 & 0.001 & 0.006 & 0.003 & 0.016 & 0.007 \\
\hline \multirow{2}{*}{ F15 } & Value & 0.160 & 0.180 & 0.080 & 0.330 & 0.110 & 0.260 & 0.170 \\
\hline & Standard error & 0.056 & 0.013 & 0.008 & 0.030 & 0.010 & 0.022 & 0.010 \\
\hline \multirow{2}{*}{ F16 } & Value & 0.110 & 0.110 & 0.050 & 0.200 & 0.070 & 0.320 & 0.280 \\
\hline & Standard error & 0.003 & 0.004 & 0.002 & 0.007 & 0.003 & 0.051 & 0.104 \\
\hline
\end{tabular}

For the whole set of experiments, the prediction errors are reported in Appendix A Table A1. Except for some runs for variables S, F, and A, all RME were lower than $15 \%$. Additionally, the average RMSE and RME values for each concentration were of the same order of magnitude as the experimental variability, here defined as the biological repeatability for run F01, for which three independent replicates were performed. These results validate the formulation and accuracy of the proposed model under the operating conditions included in the experimental design.

In the specific case of reference run F10, a comparison between the model simulation (using the corresponding parameters from Table 2) and experimental data is illustrated in Figure 5.
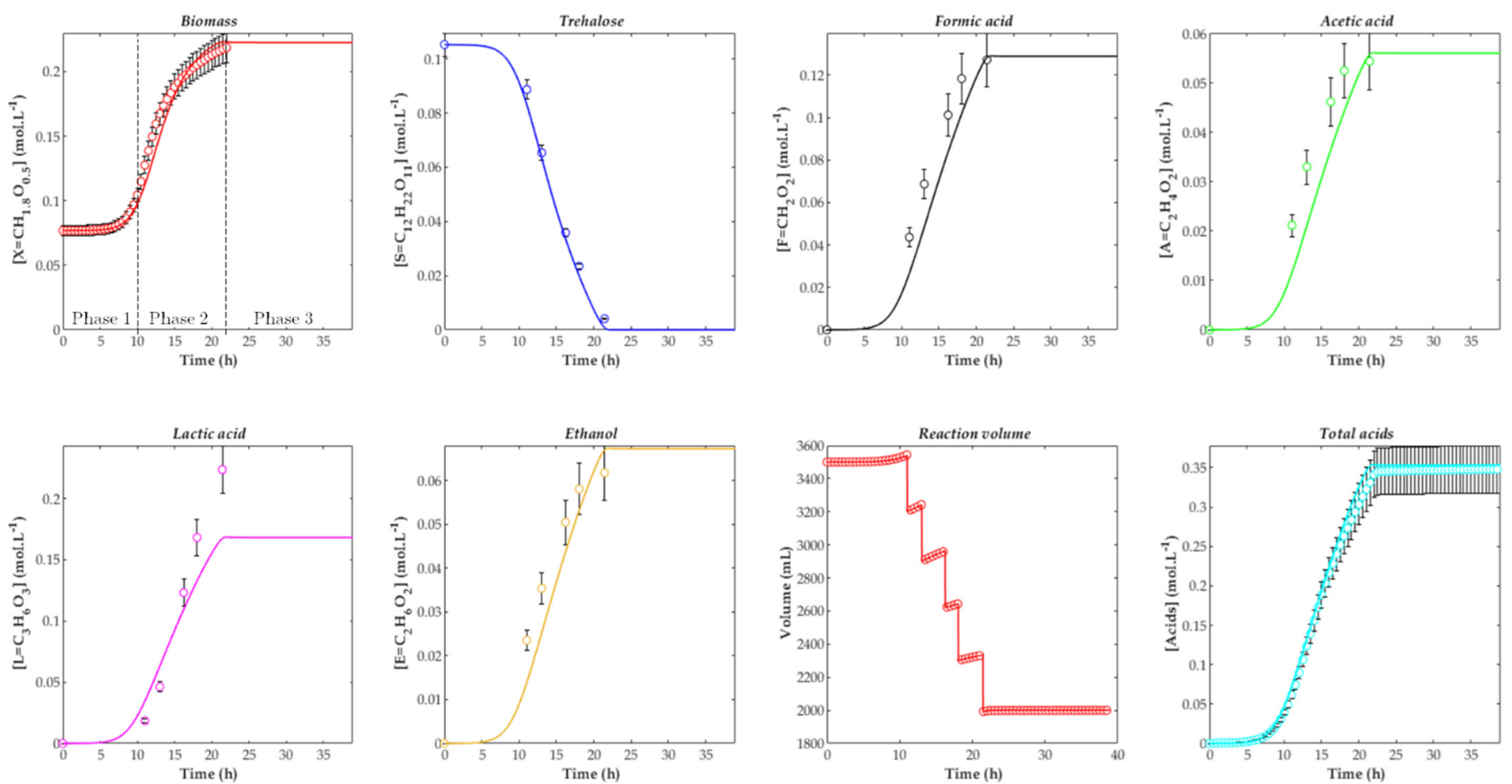

Figure 5. Evolution of concentrations over time for experiment $\mathrm{F} 10\left(\mathrm{~T}=30^{\circ} \mathrm{C}, \mathrm{pH}=8\right)$. Comparison between model (continuous line, using parameters from Tables 1 and 2) and experimental data (symbols). The error bars for data represent the biological standard deviation, calculated from three independent repetitions of the run F01. 
Three growth phases are apparent in Figure 5: a lag phase (phase 1, between 0 and $10 \mathrm{~h}$ ); a phase of active growth, substrate consumption, and metabolite production (phase 2, between $10 \mathrm{~h}$ and $21 \mathrm{~h}$ ); and a final phase where concentrations do not change over time, owing to the depletion of the carbon source or growth inhibition by metabolites (phase 3, after $21 \mathrm{~h}$ ). Regarding culture volume evolution, as already mentioned, the discrete variations at regular intervals were due to sampling for analysis of the culture medium and the gradual increase was due to $\mathrm{NaOH}$ addition for $\mathrm{pH}$ control. One can also observe that the four metabolites were produced simultaneously, with no gap for the growth dynamics. The metabolites were thus primary end products generated during a single trophophase [44]. This justifies the choice of a global inhibitor concentration (Equation (13)), which included four correlated concentrations.

In consideration of the visual fit from Figure 5, the model representation is reasonably satisfactory. The most pronounced discrepancy between the model and experimental data appears for lactic acid, for which the model predicted a lower concentration before substrate depletion. This is related to a slightly underestimated yield factor $\mathrm{Y}_{\mathrm{L} / \mathrm{S}}$.

\subsection{Response Surface Model for Parameter Dependence on Fermentation Conditions}

Model parameters were expressed as a function of temperature and $\mathrm{pH}$, according to the surface model (Equation (17)). The values of the $\beta$ regression coefficients were adjusted globally using the whole set of calibration data.

The resulting response surfaces for the seven model parameters are plotted in Figure 6. For the five kinetic parameters, (i.e., the maximum specific growth and production rates), the response surfaces have the same convex shape, with a well-defined maximum value at intermediate $\mathrm{T}$ and $\mathrm{pH}$ conditions. These maxima likely indicate the optimal temperatures and $\mathrm{pH}$ for cellular growth, as well as the enzymatic activity catalyzing each of the reactions, leading to the production of the different metabolites (Figure 1).

Concerning the inhibition concentrations, the response surface for $\mathrm{K}_{\mathrm{Im}}$ has a concave shape with a local minimum, whereas that of $\mathrm{K}_{\mathrm{IX}}$ resembles a saddle surface. For this latter case, the surface shape indicates that for every $\mathrm{pH}$ there is a $\mathrm{T}$ where $\mathrm{K}_{\mathrm{IX}}$ is minimal, and for every $\mathrm{T}$ there is a $\mathrm{pH}$ where $\mathrm{K}_{\mathrm{IX}}$ is maximal. Both $\mathrm{K}_{\mathrm{Im}}$ and $\mathrm{K}_{\mathrm{IX}}$ represent the combined effect of several inhibiting metabolites (Equations (11)-(13)) with potentially different inhibition mechanisms.
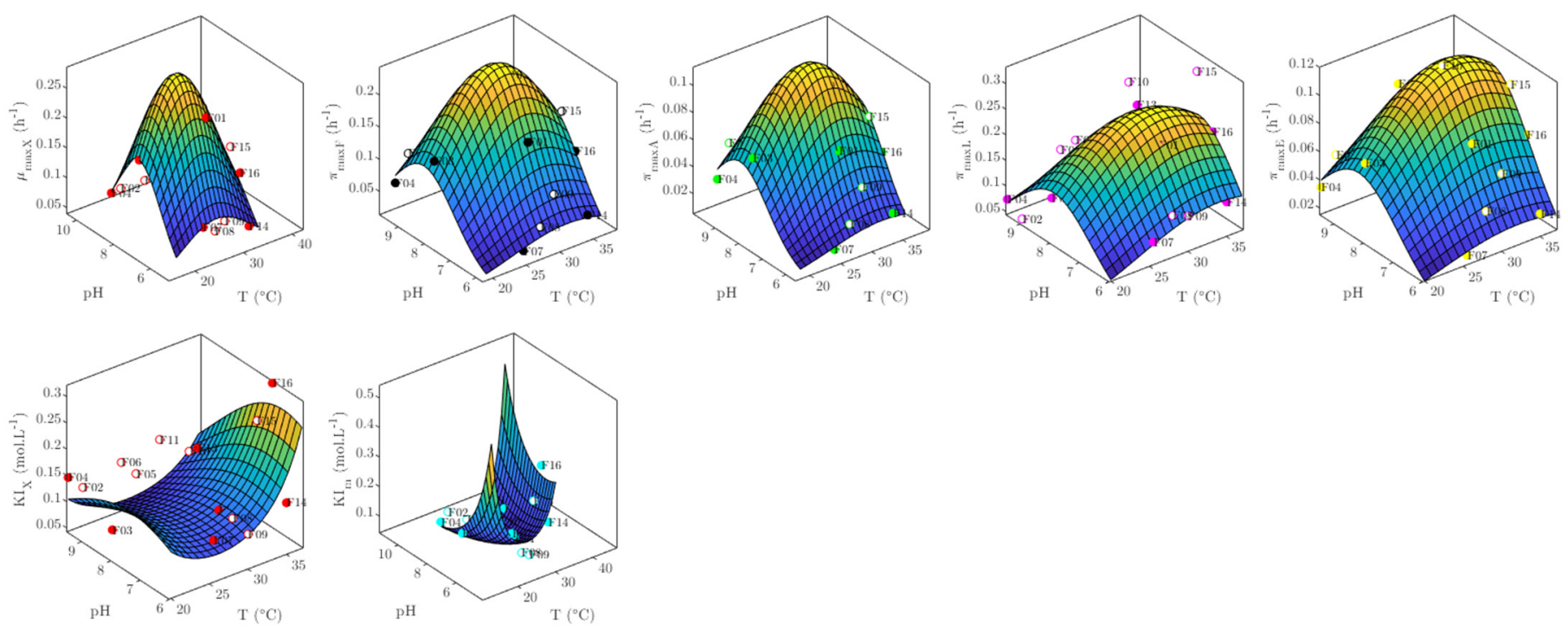

Figure 6. Response surfaces for model parameters, calculated with globally adjusted $\beta$ coefficients in Equation (17).

For completeness, the final values of the regression coefficients of Equation (17) for the seven adjustable parameters of the dynamic model are reported in Appendix A Table A2. All coefficients in Equation (17) for each model parameter were significantly different from 
zero at a 0.05 level. A comparison between the parameter values determined for each experiment (Section 4.1) and the parameter values computed with Equation (17) (from globally adjusted $\beta$ coefficients) is depicted in Appendix A Figure A1. The goodness of the fit was assessed through the coefficient of determination, $R^{2}$. This coefficient is higher than 0.89 for six out of seven model parameters, which is a high threshold for biological data. In the case of $\mathrm{K}_{\mathrm{Im}}$, only $66 \%$ of the variance of this parameter was explained by variables $\mathrm{T}$ and $\mathrm{pH}$. The remaining $34 \%$ could be associated with inherent experimental variability and factors not included in the model, for instance transient variability of the inhibition and kinetics parameters and actual dependence of the fixed parameters (Table 1) with $\mathrm{T}$ and $\mathrm{pH}$ [45]. From a more general point of view, differences from experimental data could be due to features that were not represented by the mathematical model, such as population segregation, internal $\mathrm{pH}$ variability, and concentration gradients in the culture medium $[46,47]$.

\subsection{Model Validation}

The ability of the dynamic model including the parameters calculated from operating conditions (Equation (17)) to predict data of independent experiments was assessed with a set of validation experiments.

A comparison between the average RMSE values obtained in Section 4.1 (determined for each experiment) and Section 4.2 (calculated from operating conditions) for calibration and validation sets is depicted in Figure 7. In most cases, RMSE values were higher than the corresponding experimental variabilities, indicating that more complex models could capture additional phenomena not included in the present model, such as dependence of yields, saturation constants, or lag time (Table 1) on operating conditions. As one might expect, RMSE was generally lower for the calibration experiments than for the validation experiments, not used for parameter determination. However, the relative difference remained small (less than $30 \%$ ), indicating a satisfactory ability of the developed model to predict time evolution of the considered biomass, substrate, and metabolites under new conditions within the explored experimental range.
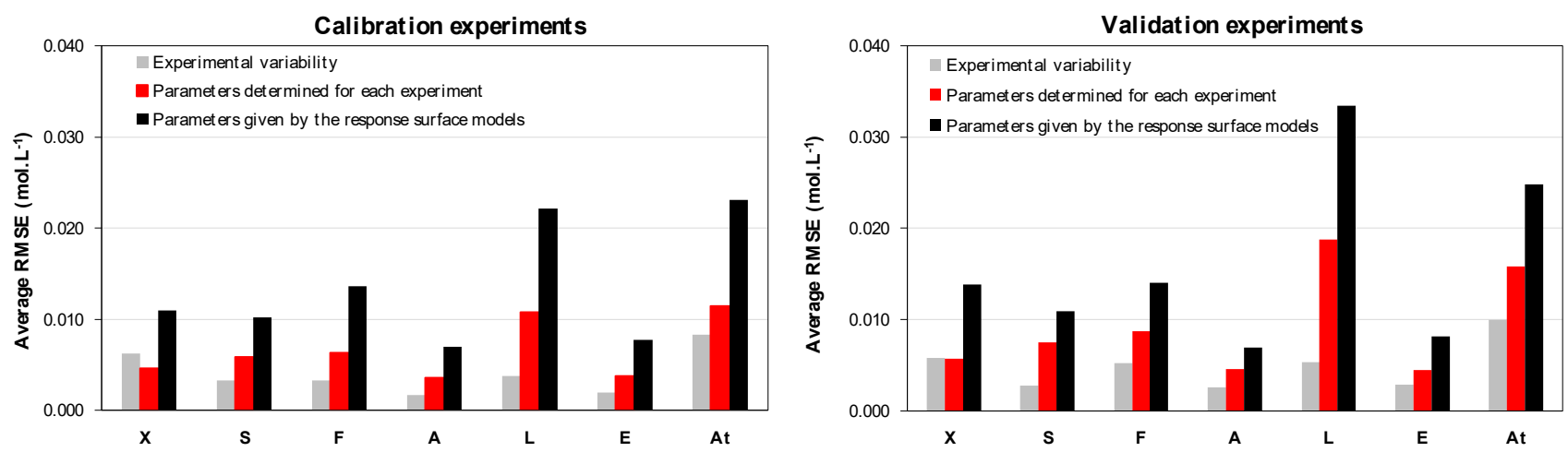

Figure 7. Comparison between experimental variability and average RMSE values for concentrations computed using parameters determined for each experiment (Table 2) and the response surface models (Table A2 and Equation (17)).

It also appears in Figure 7 that average RMSE values with parameters given by the response surface model (Table A3) are about 50\% higher than with parameters determined separately for each experiment (Table A1), for both calibration and validation sets. This result could be expected since in the global calibration step, data from eight independent experiments were combined as a whole for the least squares estimation, with a detrimental effect on the individual representation of each experiment. However, results with the parameters calculated from operating conditions are the most useful in engineering purposes since they enable a quick prediction of growth and metabolites production dynamics, based on the selected combination of temperature and $\mathrm{pH}$. 
In light of this quantitative analysis, the prediction accuracy of the empirical dynamic model coupled to the regression model may be considered satisfactory within the operating domain covered in this study.

\subsection{Model-Based Optimization of Fermentation Operating Conditions for Industrial Use}

Optimal conditions for growth and metabolite production of C. maltaromaticum calculated using the developed model are summarized in Table 3. Two optimization criteria were considered: final concentrations and final productivities calculated for a $99.9 \%$ substrate consumption.

For a detailed representation of the evolution of final concentrations and productivities for biomass and metabolites with temperature and $\mathrm{pH}$, the reader is referred to Appendix $\mathrm{A}$ Figures $\mathrm{A} 2$ and $\mathrm{A} 3$. As a general trend, the highest productivities were obtained around $35^{\circ} \mathrm{C}$ and $\mathrm{pH} 7.5$, although the exact optimal conditions depended on the considered metabolite (Table 3). No general trend was readily apparent for the maximization of the final concentrations.

Table 3. Optimal conditions for growth and production of metabolites according to the developed model. In bold: targeted metabolite for each set of operating conditions. Final concentrations and productivities calculated with initial conditions: $[\mathrm{X}]_{0}=80 \mathrm{mmol} \mathrm{L}^{-1},[\mathrm{~S}]_{0}=100 \mathrm{mmol} \mathrm{L}^{-1},[\mathrm{~F}, \mathrm{~A}, \mathrm{~L}, \mathrm{E}]_{0}=0$.

\begin{tabular}{|c|c|c|c|c|c|c|c|c|c|c|c|c|c|c|c|}
\hline \multirow{2}{*}{\multicolumn{2}{|c|}{ A. Target }} & \multirow{3}{*}{$\begin{array}{c}\mathrm{T}\left({ }^{\circ} \mathbf{C}\right) \\
20.0\end{array}$} & \multirow{3}{*}{$\begin{array}{c}\mathbf{p H} \\
7.8\end{array}$} & \multicolumn{6}{|c|}{ Final Concentrations $\left(\mathrm{mmol}^{-1}\right)$} & \multicolumn{6}{|c|}{ Final Productivities $\left(\mathrm{mmol} \mathrm{L}^{-1} \cdot \mathrm{h}^{-1}\right)$} \\
\hline & & & & \multirow{2}{*}{$\frac{X}{227}$} & \multirow{2}{*}{$\frac{\mathbf{F}}{129}$} & \multirow{2}{*}{$\begin{array}{l}\text { A } \\
56\end{array}$} & \multirow{2}{*}{$\frac{\mathbf{L}}{177}$} & \multirow{2}{*}{$\begin{array}{c}\mathbf{E} \\
73\end{array}$} & \multirow{2}{*}{$\frac{\mathbf{A}_{\mathbf{T}}}{363}$} & \multirow{2}{*}{$\frac{X}{6.56}$} & \multirow{2}{*}{$\frac{\mathbf{F}}{3.73}$} & \multirow{2}{*}{$\frac{\mathbf{A}}{1.61}$} & \multirow{2}{*}{$\frac{\mathbf{L}}{5.11}$} & \multirow{2}{*}{$\begin{array}{c}\mathbf{E} \\
2.09\end{array}$} & \multirow{2}{*}{$\frac{\mathbf{A}_{\mathbf{T}}}{10.46}$} \\
\hline Biomass & $\mathrm{B}_{\text {conc. }} \uparrow$ & & & & & & & & & & & & & & \\
\hline Formic acid & $\mathrm{F}_{\text {conc. }} \uparrow$ & 28.0 & 9.5 & 133 & 176 & 89 & 123 & 94 & 387 & 1.68 & 2.20 & 1.12 & 1.54 & 1.18 & 4.86 \\
\hline Acetic acid & $\mathrm{A}_{\text {conc. } \uparrow} \uparrow$ & 28.0 & 9.5 & 133 & 176 & 89 & 123 & 94 & 387 & 1.68 & 2.20 & 1.12 & 1.54 & 1.18 & 4.86 \\
\hline Lactic acid & $\mathrm{L}_{\text {conc. }} \uparrow$ & 37.0 & 6.0 & 180 & 95 & 42 & 296 & 72 & 433 & 1.68 & 2.20 & 1.12 & 1.54 & 1.18 & 4.86 \\
\hline Ethanol & $\mathrm{E}_{\text {conc. }} \uparrow$ & 37.0 & 9.5 & 118 & 147 & 77 & 128 & 139 & 352 & 2.35 & 2.90 & 1.54 & 2.54 & 2.76 & 6.98 \\
\hline Ethanol & $\mathrm{E}_{\text {conc. } \downarrow} \downarrow$ & 27.0 & 7.6 & 217 & 143 & 62 & 166 & 68 & 372 & 6.93 & 4.57 & 1.98 & 5.31 & 2.16 & 11.86 \\
\hline Total acids & $\mathrm{A}_{\text {Tconc. }} \uparrow$ & 37.0 & 6.0 & 180 & 95 & 42 & 296 & 72 & 433 & 3.33 & 1.76 & 0.77 & 5.48 & 1.33 & 8.01 \\
\hline Total acids & $\mathrm{A}_{\text {Tconc }} \downarrow$ & 37.0 & 9.5 & 118 & 147 & 77 & 128 & 139 & 352 & 2.35 & 2.90 & 1.54 & 2.54 & 2.76 & 6.98 \\
\hline Biomass & $\mathrm{B}_{\text {prod. }} \uparrow$ & & 7.5 & 199 & 139 & 64 & 178 & 73 & 382 & 7.49 & 5.25 & 2.41 & 6.71 & 2.77 & 14.38 \\
\hline Formic acid & $\mathrm{F}_{\text {prod. } \uparrow} \uparrow$ & 34.5 & 8.0 & 178 & 148 & 71 & 163 & 82 & 381 & 6.77 & 5.61 & 2.70 & 6.18 & 3.12 & 14.48 \\
\hline Acetic acid & $\mathrm{A}_{\text {prod. }} \uparrow$ & 35.0 & 8.1 & 172 & 148 & 72 & 161 & 85 & 381 & 6.49 & 5.58 & 2.71 & 6.06 & 3.21 & 14.35 \\
\hline Lactic acid & $\mathrm{L}_{\text {prod. } \uparrow} \uparrow$ & 37.0 & 7.1 & 188 & 123 & 58 & 215 & 78 & 395 & 6.60 & 4.31 & 2.04 & 7.54 & 2.73 & 13.89 \\
\hline Ethanol & $\mathrm{E}_{\text {prod. }} \uparrow$ & 37.0 & 8.3 & 158 & 144 & 73 & 162 & 97 & 378 & 5.57 & 5.08 & 2.56 & 5.70 & 3.43 & 13.34 \\
\hline Ethanol & $\mathrm{E}_{\text {prod. } \downarrow}$ & 28.0 & 6.0 & 175 & 108 & 41 & 278 & 78 & 427 & 2.14 & 1.32 & 0.50 & 3.38 & 0.95 & 5.20 \\
\hline Total acids & $\mathrm{A}_{\text {Tprod. }} \uparrow$ & 35.5 & 7.7 & 184 & 139 & 67 & 177 & 81 & 384 & 7.16 & 5.41 & 2.59 & 6.90 & 3.13 & 14.90 \\
\hline Total acids & $\mathrm{A}_{\text {Tprod. }} \downarrow$ & 25.0 & 9.5 & 146 & 173 & 88 & 126 & 87 & 386 & 1.71 & 2.03 & 1.03 & 1.48 & 1.02 & 4.53 \\
\hline
\end{tabular}

$\uparrow$ maximization, $\downarrow$ minimization, conc.: final concentration, prod.: batch-average productivity.

These data can be useful in optimizing industrial processes involving the growth of C. maltaromaticum cells in a trehalose-based substrate. A first application consists of producing C. maltaromaticum concentrates, regardless of metabolite production. In this case two conditions of cultivation appear advisable: $20^{\circ} \mathrm{C}$ and $\mathrm{pH} 7.8$ to maximize concentration $\left(227 \mathrm{mmol}_{\mathrm{C}} \cdot \mathrm{L}^{-1}\right)$ or $33.5^{\circ} \mathrm{C}$ and $\mathrm{pH} 7.5$ in order to maximize productivity $\left(7.49 \mathrm{mmol}_{\mathrm{C}} \cdot \mathrm{L}^{-1} \cdot \mathrm{h}^{-1}\right)$ and thus the biomass production per unit of time, at the expense of a $12 \%$ reduction of the final biomass concentration $\left(199 \mathrm{mmol}_{\mathrm{C}} \cdot \mathrm{L}^{-1}\right)$. 
A second application deals with the development and parametrization of timetemperature integrators (TTI), labels in which a $\mathrm{pH}$ decline, associated with acids synthesis, entails an irreversible color change from green to red. Modulating the acidifying activity of $C$. maltaromaticum thus allows a reliable shelf-life estimation of different food products. Long shelf-lives can be tracked using TTI composed of concentrates exhibiting low acidifying activities (minimal production of total acids), while short shelf-lives can be tracked using concentrates exhibiting high acidifying activities. In the scenario of maximizing acidifying activity, the production of total acids must be favored, and thus fermentation should be carried out under two possible conditions: $37.0^{\circ} \mathrm{C}$ and $\mathrm{pH} 6.0$ to maximize their final concentration $\left(433 \mathrm{mmol} \cdot \mathrm{L}^{-1}\right)$ or $35.5^{\circ} \mathrm{C}$ and $\mathrm{pH} 7.7$ to maximize their productivity $\left(14.90 \mathrm{mmol} \cdot \mathrm{L}^{-1} \cdot \mathrm{h}^{-1}\right)$. Under these conditions, the biomass production decreases respectively by $20 \%$ and $4 \%$ with respect to its optimal values. If the objective is, on the contrary, to minimize acidifying activity, two conditions can be envisaged to favor the lowest production of total acids: $37.0^{\circ} \mathrm{C}$ and $\mathrm{pH} 9.5$ for a final concentration of $352 \mathrm{mmol} \mathrm{L}^{-1}$ or $25.0^{\circ} \mathrm{C}$ and $\mathrm{pH} 9.5$ for a final productivity of $4.53 \mathrm{mmol} \cdot \mathrm{L}^{-1} \cdot \mathrm{h}^{-1}$. Under these conditions, the mean biomass production would decrease respectively by $48 \%$ and $77 \%$ with respect to the maximal values.

Data from Table 3 show that the conditions to minimize the total acids concentration (37.0 ${ }^{\circ} \mathrm{C}$ and $\mathrm{pH}$ 9.5) coincide with those to maximize the ethanol concentration (the nonacidifying metabolite, $139 \mathrm{mmol} \mathrm{L}^{-1}$ ) and lead to a lactic acid concentration close to its minimal value $\left(128 \mathrm{mmol} \mathrm{L}^{-1}\right.$ versus the minimum around $\left.120 \mathrm{mmol} \mathrm{L}^{-1}\right)$. Conversely, when the production of total acids is maximized, the lactic acid concentration is also maximal $\left(296 \mathrm{mmol} \mathrm{L}^{-1}\right)$ and that of ethanol is close to its minimum $\left(72 \mathrm{mmol} \mathrm{L}^{-1}\right.$ versus $\left.68 \mathrm{mmol} \mathrm{L}^{-1}\right)$.

Furthermore, it should be noted that the condition $27^{\circ} \mathrm{C}$ and pH 7.6 leads both to a good biomass productivity $\left(6.93 \mathrm{mmol} \cdot \mathrm{L}^{-1} \cdot \mathrm{h}^{-1}\right.$ versus the maximum $\left.7.49 \mathrm{mmol} \cdot \mathrm{L}^{-1} \cdot \mathrm{h}^{-1}\right)$ and a low total acids concentration $\left(372 \mathrm{mmol} \mathrm{L}^{-1}\right.$ versus the minimum $352 \mathrm{mmol} \mathrm{L}^{-1}$ ). Cultivation under this condition turns out be advantageous to ally a high biomass production and a relatively low total acidification.

\section{Conclusions}

The dynamic model developed in this study is able to predict with satisfactory accuracy the growth of $C$. maltaromaticum CNCM I-3298 (average error of 10\%) as well as the conversion of trehalose into four primary metabolites (average error of $14 \%$ ) under a wide range of conditions of temperature and $\mathrm{pH}$. The interpolation capability of the model was verified with a set of eight independent validation experiments, for which the average relative error was $13 \%$.

This model constitutes a useful tool for optimizing C. maltaromaticum cultures. Based on two easily controllable parameters, $\mathrm{pH}$ and temperature, it could be implemented in industrial applications of food technology to define optimal growth and metabolite production conditions with various objectives, such as the maximization of biomass for production of bacterium concentrates or the maximization or minimization of the acidifying activity. A typical operating condition for this bacterium could be, for instance, $30.0^{\circ} \mathrm{C}$ and $\mathrm{pH}$ 7.0. If the goal is to produce bacterium concentrates, to maximize final biomass concentration, our results suggest that a quite different condition should be selected $\left(20.0^{\circ} \mathrm{C}\right.$ and $\left.\mathrm{pH} 7.8\right)$, while for maximum biomass productivity, $33.5^{\circ} \mathrm{C}$ and $\mathrm{pH} 7.5$ is most appropriate. Such results are quite difficult to anticipate from the qualitative knowledge of the bacterium alone, and a large number of time-consuming experiments would be required to locate these optimal conditions experimentally without constructing a dynamic model of the process.

The effort of developing the model is especially cost effective when a variety of scenarios are explored. If the goal is to develop time-temperature integrators (TTI) to track the cold-chain of food products, a set of labels with specific shelf-lives has to be designed for various target products. The range of desired shelf-lives can be as large as 1 to 30 days, 
requiring very different TTI designs. In a traditional approach, for each desired shelf-life duration, a range of factors such as the initial bacterium concentration and the buffer properties of the medium have to be explored in a series of relatively time-consuming experiments. In such an environment, temperature varies in an arbitrary but known way, and $\mathrm{pH}$ depends on the produced acids. The presented dynamic model can be extended to predict the moment when a specific amount of acids is produced, corresponding to the $\mathrm{pH}$-induced color change of the TTI label and hence to the desired shelf-life. Modelbased design of the TTI labels is expected to be faster and more accurate than a trial and error procedure.

On a more fundamental level, further work is required to incorporate the effect of other culture parameters, such as aeration, nutrient concentrations, or the use of a different carbon source, which may modify growth kinetics and metabolite production. Additionally, it would be relevant to deepen the understanding of inhibition mechanisms of the metabolites to give more biological significance to the associated parameters in the model.

Author Contributions: Conceptualization, C.P., A.G., F.F. and I.-C.T.; methodology, C.P., A.G., F.F., and I.-C.T.; software, C.P. and I.-C.T.; validation, C.P., A.G., S.P., F.F. and I.-C.T.; formal analysis, C.P. and I.-C.T.; investigation, C.P. and A.G.; resources, F.F. and I.-C.T.; data curation, C.P. and A.G.; writing—original draft preparation, C.P. and A.G.; writing—review and editing, C.P., A.G., S.P., F.F. and I.-C.T.; visualization, C.P., A.G. and I.-C.T.; supervision, S.P., F.F. and I.-C.T.; project administration, S.P., F.F. and I.-C.T.; funding acquisition, S.P. and F.F. All authors have read and agreed to the published version of the manuscript.

Funding: This study received funding from the European Union's Horizon 2020 Marie SkłodowskaCurie research and innovation program under grant agreement no. 777657.

Data Availability Statement: The data presented in this study are available on request from the corresponding author. The data are not publicly available due to an ongoing research project.

Acknowledgments: The authors thank Marie-Nöelle Lecercq-Perlat for HPLC analysis.

Conflicts of Interest: The authors declare no conflict of interest. The funders had no role in the design of the study; in the collection, analyses, or interpretation of data; in the writing of the manuscript; or in the decision to publish the results.

\section{Nomenclature}

\begin{tabular}{|c|c|}
\hline A & Acetic acid \\
\hline $\mathrm{E}$ & Ethanol \\
\hline $\mathrm{F}$ & Formic acid \\
\hline $\mathrm{L}$ & Lactic acid \\
\hline S & Carbon substrate (trehalose) \\
\hline $\mathrm{X}$ & Biomass \\
\hline $\mathrm{E}_{\mathrm{A}}$ & Enzymatic activation factor \\
\hline $\mathrm{C}\left(\mathrm{mol} \cdot \mathrm{L}^{-1}\right)$ & $\begin{array}{l}\text { Concentration (in the calculation of errors and the definition of the } \\
\text { inhibition factors) }\end{array}$ \\
\hline [i] $\left(\mathrm{mol} \cdot \mathrm{L}^{-1}\right)$ & $\begin{array}{l}\text { Concentration of species i (substrate, metabolite, biomass) in the culture } \\
\text { medium (in the system of differential equations) }\end{array}$ \\
\hline$I_{m}$ & Production inhibition factor of metabolite $\mathrm{m}$ \\
\hline $\mathrm{I}_{X}$ & Biomass growth inhibition factor \\
\hline $\mathrm{K}_{\mathrm{Im}}\left(\mathrm{mol} \cdot \mathrm{L}^{-1}\right)$ & Concentration for $50 \%$ production rate inhibition of metabolite $\mathrm{m}$ \\
\hline $\mathrm{K}_{\mathrm{IX}}\left(\mathrm{mol}_{\mathrm{C}} \cdot \mathrm{L}^{-1}\right)$ & Concentration for $50 \%$ growth rate inhibition of biomass \\
\hline
\end{tabular}




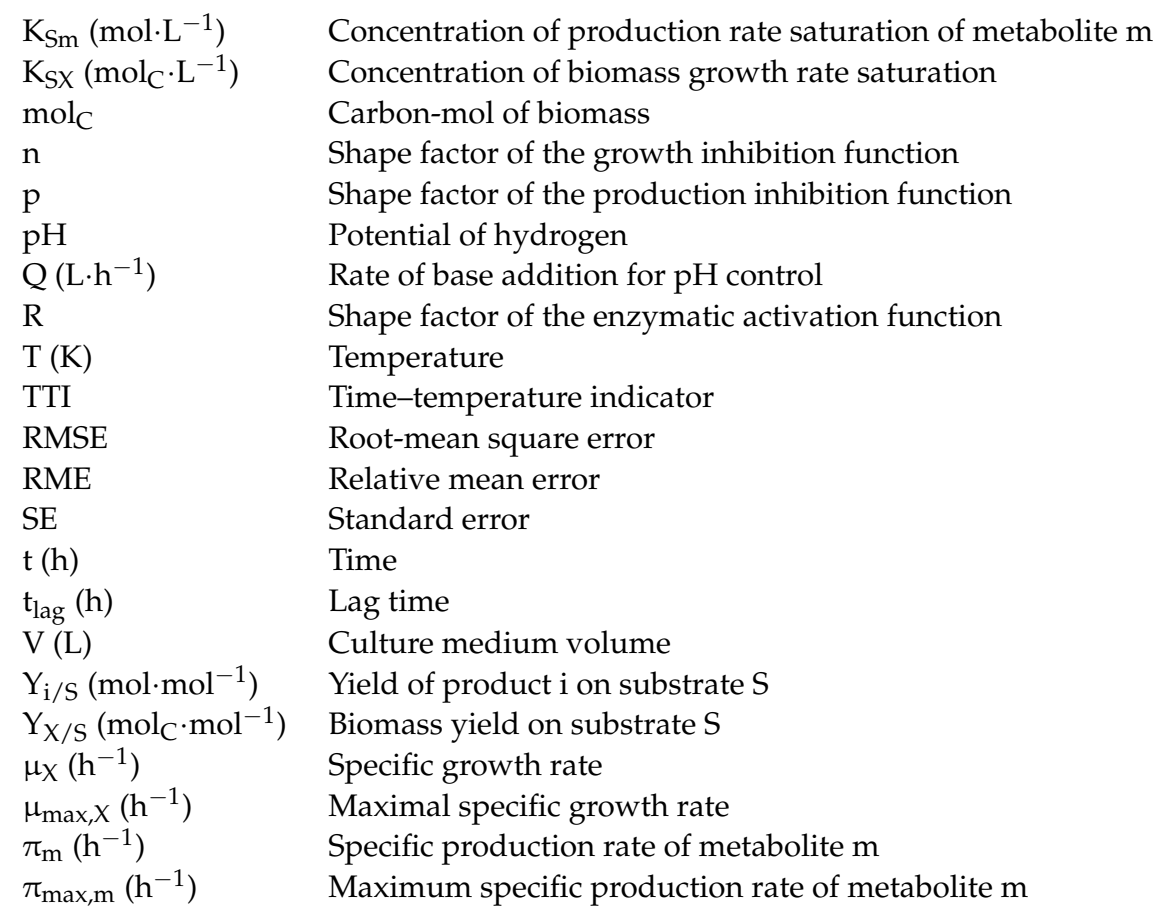

Appendix A.

Appendix A.1. Model Parameter Identification

Table A1. Residual modelling error with model parameters determined for each experiment and summarized in Table 2.

\begin{tabular}{|c|c|c|c|c|c|c|c|c|c|c|c|c|c|c|}
\hline & \multicolumn{7}{|c|}{ RMSE $\left(\right.$ Mol L $\left.^{-1}\right)$} & \multicolumn{7}{|c|}{ RME (\%) } \\
\hline & $X$ & $\mathbf{S}$ & F & $\mathbf{A}$ & $\mathbf{L}$ & E & $\begin{array}{c}\text { A } \\
\text { Total }\end{array}$ & $X$ & S & F & $\mathbf{A}$ & $\mathbf{L}$ & E & A Total \\
\hline F01 & 0.008 & 0.006 & 0.010 & 0.007 & 0.022 & 0.007 & 0.033 & 4 & 4 & 7 & 13 & 6 & 10 & 7 \\
\hline F02 & 0.005 & 0.007 & 0.006 & 0.003 & 0.004 & 0.003 & 0.005 & 4 & 16 & 8 & 8 & 8 & 7 & 3 \\
\hline F03 & 0.005 & 0.006 & 0.003 & 0.001 & 0.003 & 0.001 & 0.006 & 4 & 9 & 3 & 2 & 3 & 2 & 1 \\
\hline F04 & 0.006 & 0.006 & 0.003 & 0.001 & 0.005 & 0.002 & 0.005 & 7 & 13 & 5 & 5 & 6 & 6 & 3 \\
\hline F05 & 0.008 & 0.005 & 0.014 & 0.007 & 0.027 & 0.007 & 0.034 & 4 & 4 & 9 & 11 & 10 & 9 & 8 \\
\hline F06 & 0.006 & 0.004 & 0.012 & 0.005 & 0.024 & 0.006 & 0.012 & 5 & 2 & 7 & 7 & 8 & 8 & 3 \\
\hline F07 & 0.006 & 0.007 & 0.011 & 0.006 & 0.009 & 0.006 & 0.007 & 4 & 5 & 14 & 33 & 4 & 11 & 2 \\
\hline F08 & 0.006 & 0.007 & 0.011 & 0.005 & 0.030 & 0.004 & 0.003 & 4 & 5 & 17 & 23 & 8 & 7 & 1 \\
\hline F09 & 0.004 & 0.005 & 0.002 & 0.001 & 0.002 & 0.002 & 0.003 & 7 & 17 & 6 & 7 & 5 & 6 & 2 \\
\hline F10 & 0.005 & 0.009 & 0.006 & 0.004 & 0.028 & 0.004 & 0.026 & 3 & 7 & 4 & 7 & 9 & 5 & 6 \\
\hline F11 & 0.003 & 0.018 & 0.009 & 0.005 & 0.011 & 0.006 & 0.032 & 3 & 27 & 9 & 10 & 9 & 11 & 6 \\
\hline F12 & 0.005 & 0.013 & 0.002 & 0.001 & 0.003 & 0.001 & 0.004 & 13 & 61 & 3 & 4 & 8 & 2 & 2 \\
\hline F13 & 0.002 & 0.006 & 0.012 & 0.005 & 0.024 & 0.005 & 0.007 & 2 & 4 & 7 & 6 & 6 & 5 & 2 \\
\hline F14 & 0.003 & 0.003 & 0.009 & 0.005 & 0.012 & 0.006 & 0.015 & 4 & 3 & 16 & 20 & 5 & 12 & 4 \\
\hline F15 & 0.009 & 0.005 & 0.009 & 0.006 & 0.023 & 0.005 & 0.011 & 5 & 4 & 7 & 13 & 8 & 8 & 2 \\
\hline F16 & 0.003 & 0.001 & 0.001 & 0.001 & 0.008 & 0.001 & 0.014 & 2 & 1 & 2 & 4 & 6 & 2 & 3 \\
\hline Mean & 0.005 & 0.007 & 0.008 & 0.004 & 0.015 & 0.004 & 0.014 & 5 & 11 & 8 & 11 & 7 & 7 & 4 \\
\hline
\end{tabular}

Response surface model for parameter dependence on fermentation conditions. 
Table A2. Response surface coefficients fitted to experimental data by multiple regression.

\begin{tabular}{|c|c|c|c|c|c|c|c|c|}
\hline Variable & Coefficient & $\mu_{\max }\left(h^{-1}\right)$ & $\pi_{\operatorname{maxF}}\left(\mathrm{h}^{-1}\right)$ & $\pi_{\operatorname{maxA}}\left(\mathrm{h}^{-1}\right)$ & $\pi_{\operatorname{maxL}}\left(\mathrm{h}^{-1}\right)$ & $\pi_{\operatorname{maxE}}\left(\mathrm{h}^{-1}\right)$ & $\mathrm{KI}_{X}\left(\mathrm{Mol} \mathrm{L}^{-1}\right)$ & $\mathrm{KI}_{\mathrm{m}}\left(\mathrm{Mol} \mathrm{L}^{-1}\right)$ \\
\hline \multirow{2}{*}{ Constant } & Value $\left(\beta_{0}\right)$ & $-1.38 \times 10^{1}$ & $-1.64 \times 10^{1}$ & $-1.74 \times 10^{1}$ & $-1.21 \times 10^{1}$ & $-1.12 \times 10^{1}$ & $-8.61 \times 10^{-1}$ & $1.19 \times 10^{1}$ \\
\hline & Standard error & $0.05 \times 10^{1}$ & $0.07 \times 10^{1}$ & $0.09 \times 10^{1}$ & $0.09 \times 10^{1}$ & $0.07 \times 10^{1}$ & $0.05 \times 10^{-1}$ & $0.03 \times 10^{1}$ \\
\hline \multirow[b]{2}{*}{$\mathrm{T}$} & Value $\left(\beta_{1}\right)$ & $2.63 \times 10^{-1}$ & $2.66 \times 10^{-1}$ & $2.71 \times 10^{-1}$ & $1.82 \times 10^{-1}$ & $1.27 \times 10^{-1}$ & $-1.87 \times 10^{-1}$ & $-5.80 \times 10^{-1}$ \\
\hline & Standard error & $0.13 \times 10^{-1}$ & $0.26 \times 10^{-1}$ & $0.28 \times 10^{-1}$ & $0.23 \times 10^{-1}$ & $0.14 \times 10^{-1}$ & $0.05 \times 10^{-1}$ & $0.17 \times 10^{-1}$ \\
\hline \multirow{2}{*}{$\mathrm{pH}$} & Value $\left(\beta_{2}\right)$ & $2.42 \times 10^{0}$ & $2.89 \times 10^{0}$ & $3.01 \times 10^{0}$ & $2.27 \times 10^{0}$ & $2.02 \times 10^{0}$ & $6.65 \times 10^{-1}$ & $-1.27 \times 10^{0}$ \\
\hline & Standard error & $0.11 \times 10^{0}$ & $0.14 \times 10^{0}$ & $0.19 \times 10^{0}$ & $0.16 \times 10^{0}$ & $0.13 \times 10^{0}$ & $0.45 \times 10^{-1}$ & $0.16 \times 10^{0}$ \\
\hline \multirow{2}{*}{$\mathrm{T}^{2}$} & Value $\left(\beta_{3}\right)$ & $-4.26 \times 10^{-3}$ & $-3.45 \times 10^{-3}$ & $-3.26 \times 10^{-3}$ & $-2.05 \times 10^{-3}$ & $-1.92 \times 10^{-3}$ & $3.97 \times 10^{-3}$ & $7.95 \times 10^{-3}$ \\
\hline & Standard error & $0.13 \times 10^{-3}$ & $0.32 \times 10^{-3}$ & $0.33 \times 10^{-3}$ & $0.81 \times 10^{-3}$ & $0.22 \times 10^{-3}$ & $0.09 \times 10^{-3}$ & $0.32 \times 10^{-3}$ \\
\hline \multirow{2}{*}{$\mathrm{pH}^{2}$} & Value $\left(\beta_{4}\right)$ & $-1.46 \times 10^{-1}$ & $-1.63 \times 10^{-1}$ & $-1.66 \times 10^{-1}$ & $-1.34 \times 10^{-1}$ & $-1.22 \times 10^{-1}$ & $-4.03 \times 10^{-2}$ & $4.35 \times 10^{-2}$ \\
\hline & Standard error & $0.06 \times 10^{-1}$ & $0.10 \times 10^{-1}$ & $0.12 \times 10^{-1}$ & $0.10 \times 10^{-1}$ & $0.09 \times 10^{-1}$ & $0.31 \times 10^{-2}$ & $0.55 \times 10^{-2}$ \\
\hline \multirow{2}{*}{$\mathrm{T} \cdot \mathrm{pH}$} & Value $\left(\beta_{5}\right)$ & $-3.53 \times 10^{-3}$ & $-7.58 \times 10^{-3}$ & $-9.17 \times 10^{-3}$ & $-7.22 \times 10^{-3}$ & $-4.68 \times 10^{-3}$ & $-3.54 \times 10^{-3}$ & $1.86 \times 10^{-2}$ \\
\hline & Standard error & $0.11 \times 10^{-3}$ & $0.97 \times 10^{-3}$ & $1.17 \times 10^{-3}$ & $0.91 \times 10^{-3}$ & $0.05 \times 10^{-3}$ & $0.06 \times 10^{-3}$ & $0.01 \times 10^{-2}$ \\
\hline
\end{tabular}
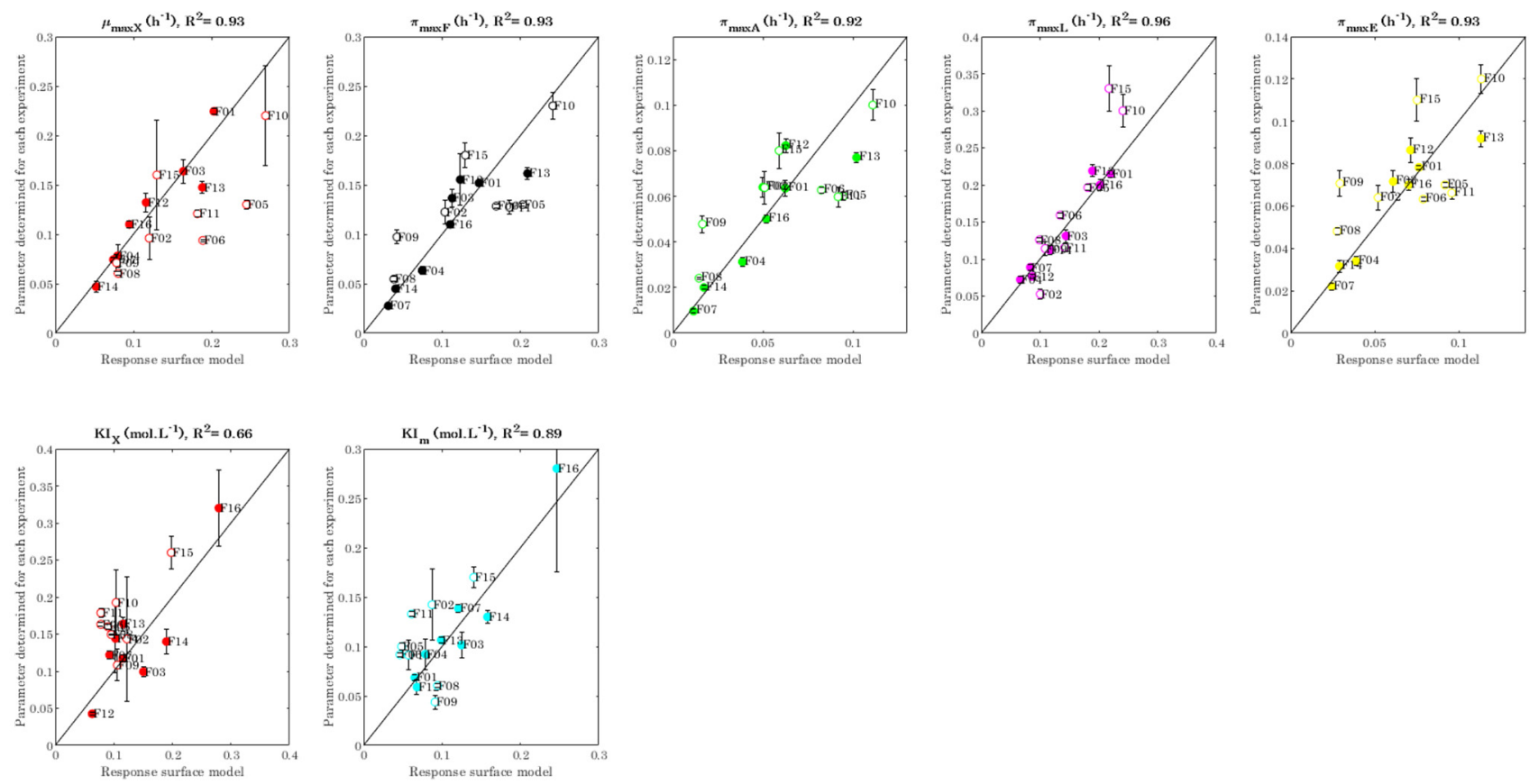

Figure A1. Comparison between model parameters determined for each experiment (Table 2) and parameters computed with the response surface models (Equation (17) using coefficients in Table A2). 


\section{Appendix A.2. Model Validation}

Error indicators RMSE and RME for calibration and validation sets are summarized in Appendix A Table A3. The RME values varied from $1 \%$ to $53 \%$, with an average of $15 \%$ for calibration set and $13 \%$ for validation set. Likewise, the average RME was lower than $15 \%$ for most of experiments, except for runs F12 (17\%), F15 (18\%), F09 (20\%), and F16 (34\%). Considering both calibration and validation sets, the average RME was 10\% for biomass and $14 \%$ for substrate and metabolites.

Table A3. Quality of fit of the model with parameters computed with the response surface models.

\begin{tabular}{|c|c|c|c|c|c|c|c|c|c|c|c|c|c|c|c|}
\hline \multirow{2}{*}{\multicolumn{2}{|c|}{ Fermentation }} & \multicolumn{7}{|c|}{ RMSE (Mol L-1) } & \multicolumn{7}{|c|}{ RME (\%) } \\
\hline & & $X$ & $\mathbf{S}$ & $\mathbf{F}$ & A & $\mathbf{L}$ & $\mathbf{E}$ & At & $x$ & $\mathbf{S}$ & $\mathbf{F}$ & $\mathbf{A}$ & $\mathbf{L}$ & $\mathbf{E}$ & At \\
\hline \multirow{9}{*}{ Calibration } & F01 & 0.010 & 0.010 & 0.021 & 0.010 & 0.041 & 0.014 & 0.033 & 5 & 6 & 14 & 20 & 10 & 18 & 7 \\
\hline & F03 & 0.021 & 0.009 & 0.008 & 0.005 & 0.008 & 0.003 & 0.012 & 15 & 14 & 7 & 9 & 7 & 5 & 4 \\
\hline & F04 & 0.005 & 0.010 & 0.009 & 0.006 & 0.007 & 0.005 & 0.015 & 5 & 26 & 18 & 23 & 9 & 17 & 9 \\
\hline & F07 & 0.012 & 0.009 & 0.010 & 0.006 & 0.015 & 0.006 & 0.009 & 9 & 8 & 13 & 31 & 5 & 10 & 3 \\
\hline & F12 & 0.003 & 0.011 & 0.008 & 0.005 & 0.003 & 0.004 & 0.009 & 8 & 53 & 13 & 16 & 8 & 11 & 6 \\
\hline & F13 & 0.010 & 0.007 & 0.006 & 0.003 & 0.036 & 0.003 & 0.011 & 7 & 5 & 4 & 4 & 8 & 4 & 2 \\
\hline & F14 & 0.015 & 0.002 & 0.013 & 0.007 & 0.004 & 0.009 & 0.012 & 20 & 2 & 23 & 28 & 2 & 16 & 3 \\
\hline & F16 & 0.011 & 0.023 & 0.033 & 0.014 & 0.064 & 0.018 & 0.085 & 9 & 33 & 50 & 45 & 48 & 38 & 18 \\
\hline & Mean & 0.011 & 0.010 & 0.014 & 0.007 & 0.022 & 0.008 & 0.023 & 10 & 18 & 18 & 22 & 12 & 15 & 7 \\
\hline \multirow{9}{*}{ Validation } & F02 & 0.005 & 0.003 & 0.017 & 0.009 & 0.008 & 0.009 & 0.007 & 5 & 8 & 20 & 22 & 15 & 21 & 4 \\
\hline & F05 & 0.011 & 0.008 & 0.007 & 0.006 & 0.045 & 0.005 & 0.016 & 7 & 7 & 4 & 8 & 13 & 8 & 4 \\
\hline & F06 & 0.008 & 0.009 & 0.013 & 0.005 & 0.044 & 0.007 & 0.032 & 6 & 5 & 7 & 6 & 11 & 9 & 6 \\
\hline & F08 & 0.009 & 0.010 & 0.012 & 0.006 & 0.026 & 0.008 & 0.003 & 7 & 8 & 19 & 25 & 8 & 14 & 1 \\
\hline & F09 & 0.011 & 0.006 & 0.005 & 0.004 & 0.018 & 0.004 & 0.009 & 19 & 22 & 15 & 24 & 35 & 15 & 7 \\
\hline & F10 & 0.021 & 0.014 & 0.025 & 0.011 & 0.063 & 0.014 & 0.044 & 11 & 10 & 17 & 18 & 20 & 20 & 10 \\
\hline & F11 & 0.018 & 0.013 & 0.007 & 0.003 & 0.017 & 0.004 & 0.050 & 16 & 20 & 7 & 6 & 12 & 8 & 9 \\
\hline & F15 & 0.028 & 0.023 & 0.026 & 0.010 & 0.047 & 0.014 & 0.036 & 15 & 20 & 22 & 21 & 17 & 21 & 7 \\
\hline & Mean & 0.014 & 0.011 & 0.014 & 0.007 & 0.033 & 0.008 & 0.025 & 11 & 13 & 14 & 16 & 16 & 15 & 6 \\
\hline
\end{tabular}

Model-based optimization of fermentation conditions. 

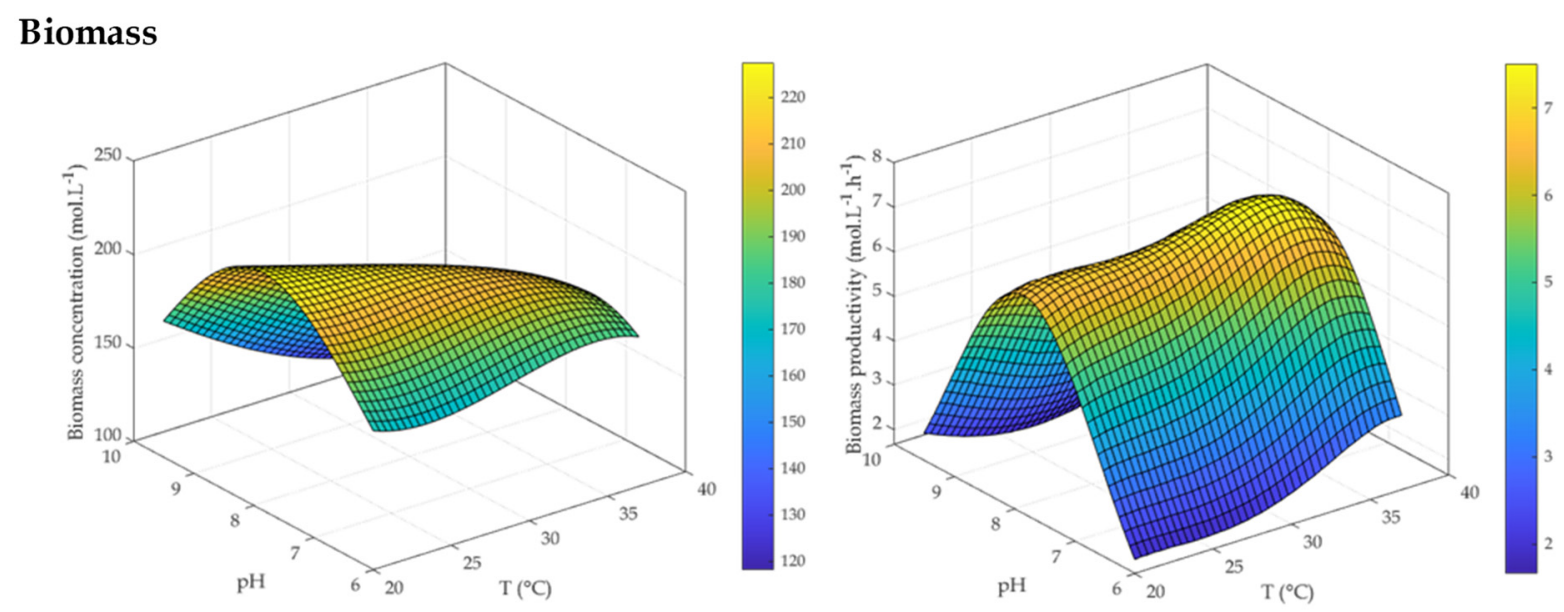

\section{Formic acid}
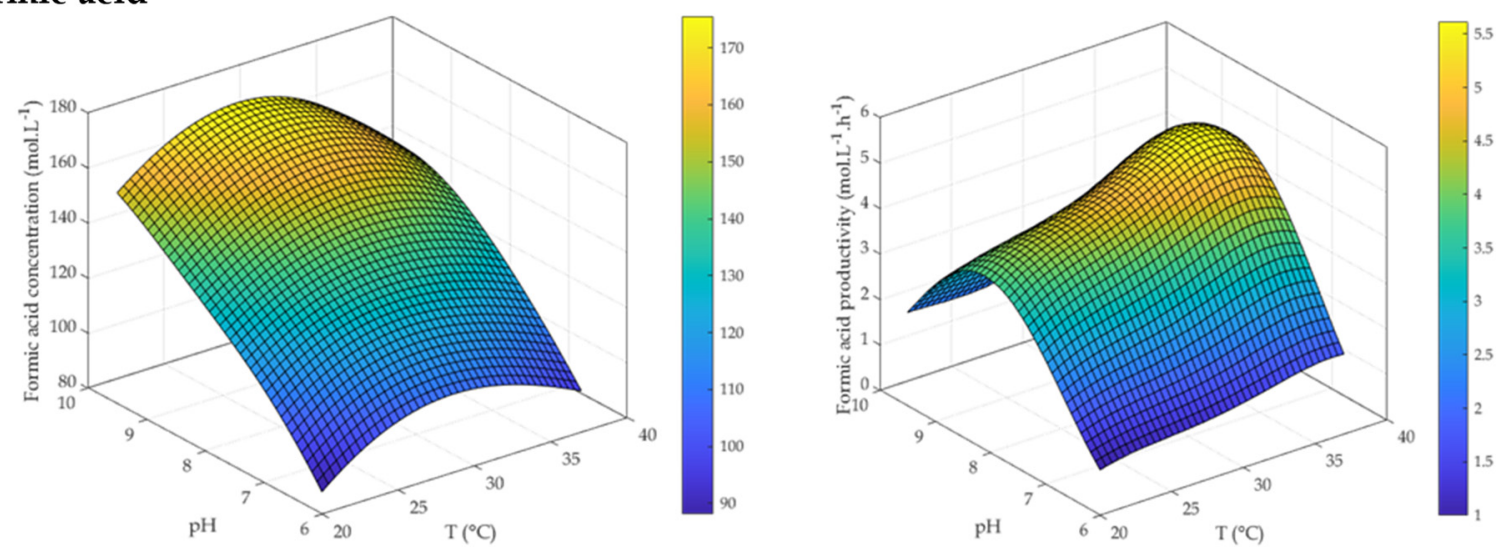

\section{Acetic acid}
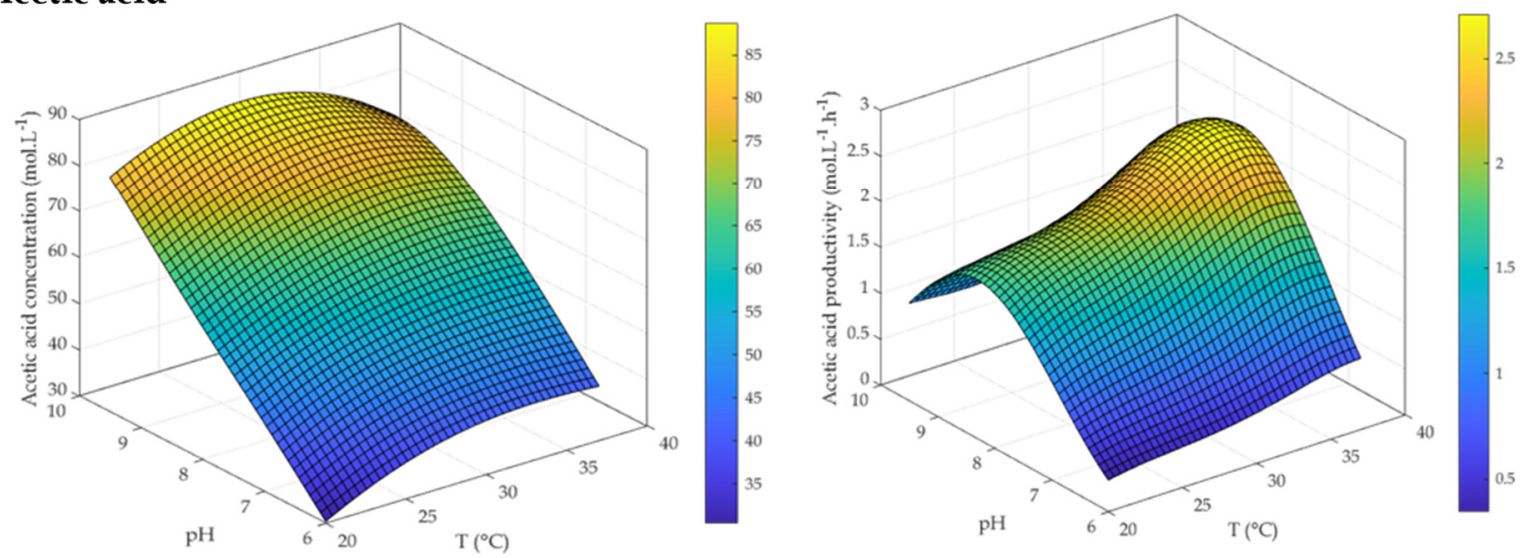

Figure A2. Evolution of final concentrations (left) and batch-average productivities (right) with temperature and $\mathrm{pH}$ for biomass, formic acid, and acetic acid. 

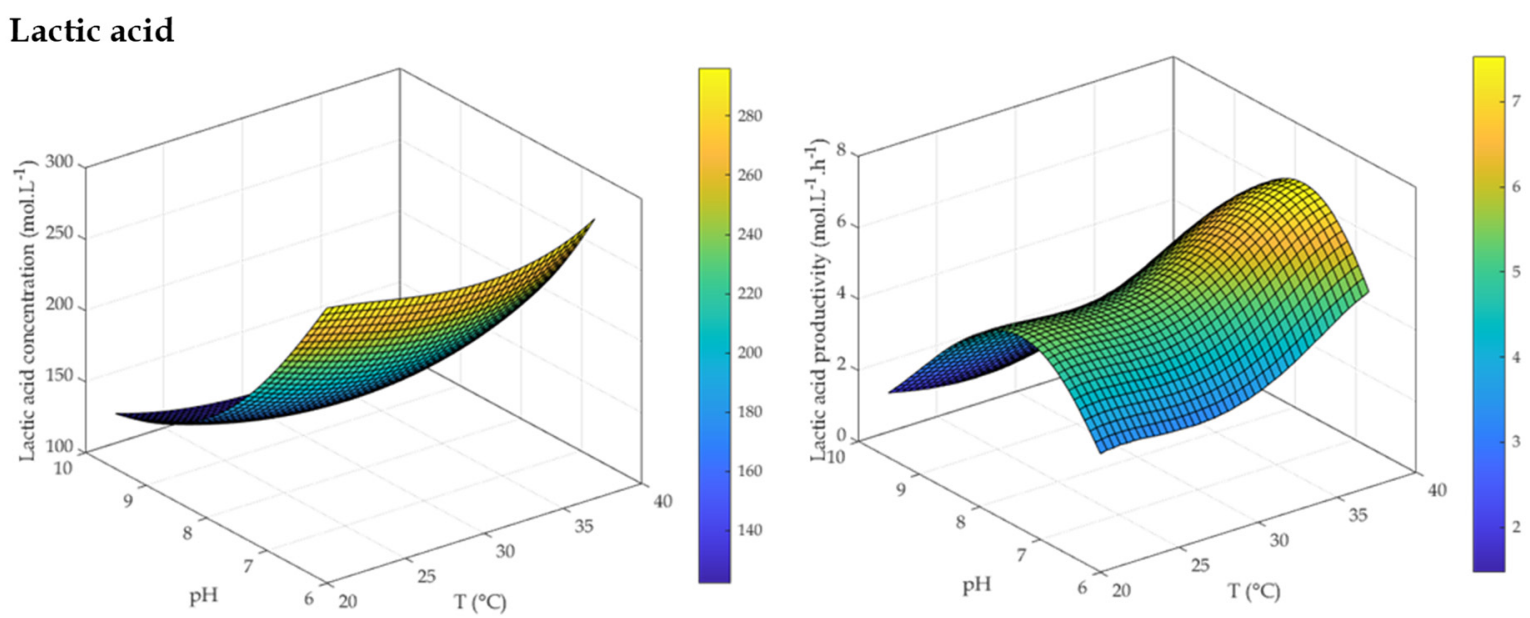

\section{Ethanol}
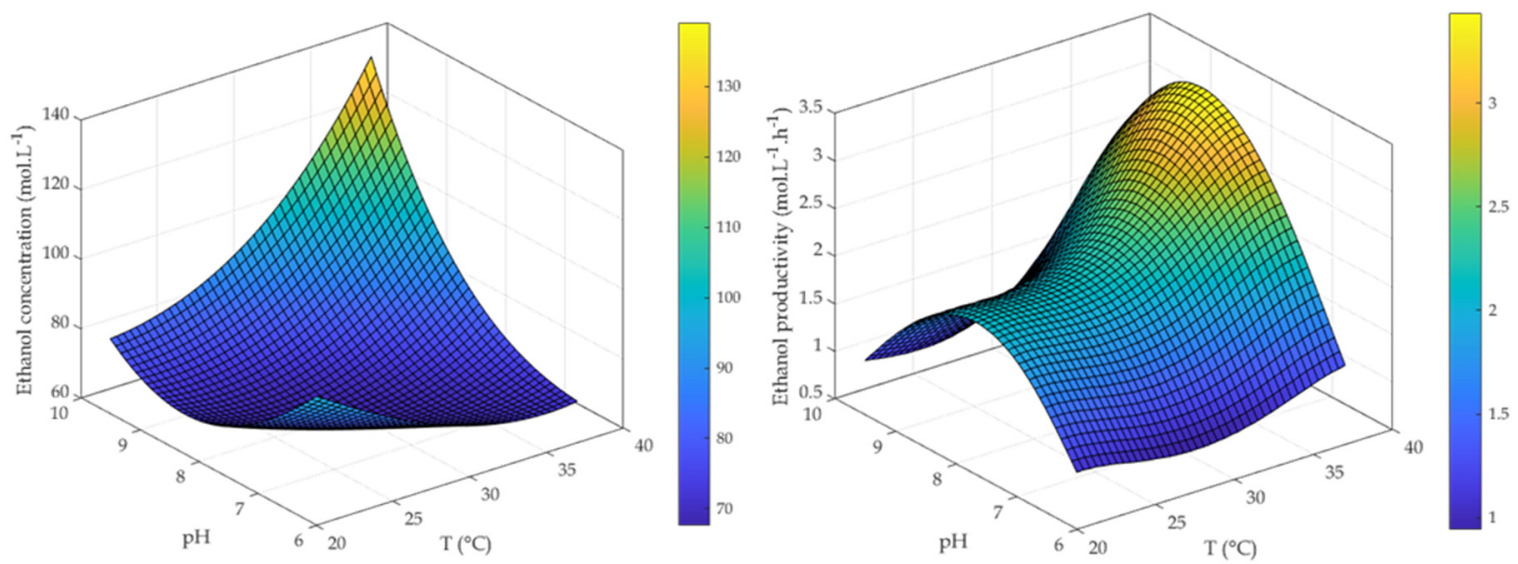

Total acids
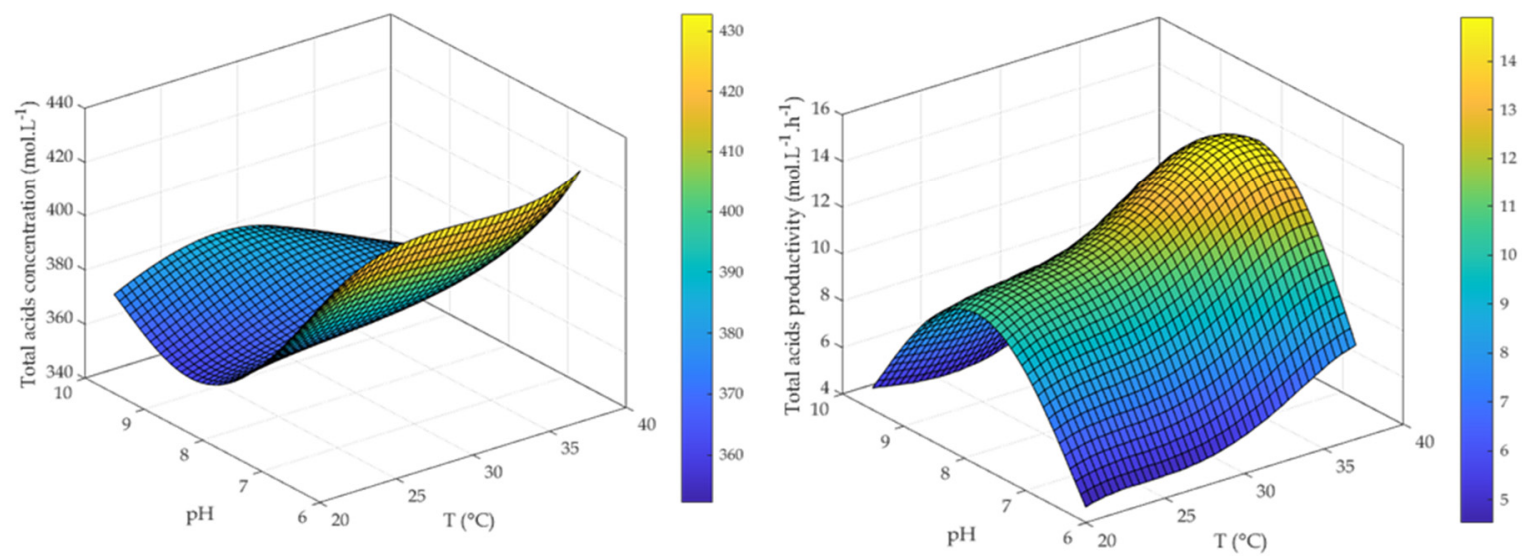

Figure A3. Evolution of final concentrations (left) and batch-average productivities (right) with temperature and $\mathrm{pH}$ for lactic acid, ethanol, and total acids.

\section{References}

1. Edima, H.; Cailliez-Grimal, C.; Revol-Junelles, A.-M.; Tonti, L.; Linder, M.; Millière, J.B. A selective enumeration medium for Carnobacterium maltaromaticum. J. Microbiol. Methods 2007, 68, 516-521. [CrossRef]

2. Afzal, M.; Jacquet, T.; Delaunay, S.; Borges, F.; Millière, J.B.; Revol-Junelles, A.M.; Cailliez-Grimal, C. Carnobacterium maltaromaticum: Identification, isolation tools, ecology and technological aspects in dairy products. Food Microbiol. 2010, 27, 573-579. [CrossRef] 
3. Cailliez-Grimal, C.; Edima, H.; Revol-Junelles, A.-M.; Millière, J.-B. Carnobacterium maltaromaticum: The Only Carnobacterium Species in French Ripened Soft Cheeses as Revealed by Polymerase Chain Reaction Detection. J. Dairy Sci. 2007, 90, 1133-1138. [CrossRef]

4. Edima, H.; Cailliez-Grimal, C.; Revol-Junelles, A.M.; Rondags, E.; Millière, J.B. Impact of pH and Temperature on the Acidifying Activity of Carnobacterium Maltaromaticum. J. Dairy Sci. 2008, 91, 3806-3813. [CrossRef]

5. Taoukis, P.; Labuza, T. Applicability of Time-Temperature Indicators as Shelf Life Monitors of Food Products. J. Food Sci. 1989, 54, 783-788. [CrossRef]

6. Ellouze, M.; Pichaud, M.; Bonaiti, C.; Coroller, L.; Couvert, O.; Thuault, D.; Vaillant, R. Modelling pH evolution and lactic acid production in the growth medium of a lactic acid bacterium: Application to set a biological TTI. Int. J. Food Microbiol. 2008, 128, 101-107. [CrossRef]

7. Girardeau, A.; Puentes, C.; Keravec, S.; Peteuil, P.; Trelea, I.C.; Fonseca, F. Influence of culture conditions on the technological properties of Carnobacterium maltaromaticum CNCM I-3298 starters. J. Appl. Microbiol. 2019, 126, 1468-1479. [PubMed]

8. Borch, E.; Molin, G. The aerobic growth and product formation of Lactobacillus, Leuconostoc, Brochothrix, and Carnobacterium in batch cultures. Appl. Microbiol. Biotechnol. 1989, 30, 81-88. [CrossRef]

9. dos Reis, F.B.; de Souza, V.M.; Thomaz, M.R.S.; Fernandes, L.P.; de Oliveira, W.P.; de Martinis, E.C.P. Use of Carnobacterium maltaromaticum cultures and hydroalcoholic extract of Lippia sidoides Cham. Against Listeria monocytogenes in fish model systems. Int. J. Food Microbiol. 2011, 146, 228-234. [CrossRef] [PubMed]

10. Afzal, M.I.; Delaunay, S.; Paris, C.; Borges, F.; Revol-Junelles, A.M.; Cailliez-Grimal, C. Identification of metabolic pathways involved in the biosynthesis of flavor compound 3-methylbutanal from leucine catabolism by Carnobacterium maltaromaticum LMA 28. Int. J. Food Microbiol. 2012, 157, 332-339. [CrossRef]

11. Afzal, M.I.; Boulahya, K.A.; Paris, C.; Delaunay, S.; Cailliez-Grimal, C. Effect of oxygen on the biosynthesis of flavor compound 3-methylbutanal from leucine catabolism during batch culture in Carnobacterium maltaromaticum LMA 28. J. Dairy Sci. 2013, 96, 352-359. [CrossRef]

12. Rahman, A.; Gleinser, M.; Lanhers, M.-C.; Riedel, C.U.; Foligne, B.; Hanse, M.; Yen, F.T.; Klouj, A.; Afzal, M.I.; Back, A.; et al. Adaptation of the lactic acid bacterium Carnobacterium maltaromaticum LMA 28 to the mammalian gastrointestinal tract: From survival in mice to interactions with human cells. Int. Dairy J. 2014, 34, 93-99.

13. Rahman, A.; El Kheir, S.M.; Back, A.; Mangavel, C.; Revoljunelles, A.-M.; Borges, F. Repeat-based bequence typing of Carnobacterium maltaromaticum. Int. J. Food Microbiol. 2016, 226, 1-4. [CrossRef] [PubMed]

14. Zhang, P.; Badoni, M.; Gänzle, M.; Yang, X. Growth of Carnobacterium spp. isolated from chilled vacuum-packaged meat under relevant acidic conditions. Int. J. Food Microbiol. 2018, 286, 120-127.

15. De Bruyn, I.N.; Louw, A.I.; Visser, L.; Holzapfel, W.H. Lactobacillus divergens is a homofermentative organism. Syst. Appl. Microbiol. 1987, 9, 173-175. [CrossRef]

16. De Bruyn, I.N.; Holzapfel, W.H.; Visser, L.; Louw, A.I. Glucose metabolism by Lactobacillus divergens. J. Gen. Microbiol. 1988, 134, 2103-2109. [CrossRef]

17. Leisner, J.J.; Laursen, B.G.; Prévost, H.; Drider, D.; Dalgaard, P. Carnobacterium: Positive and negative effects in the environment and in foods. FEMS Microbiol. Rev. 2007, 31, 592-613. [CrossRef]

18. Schillinger, U.; Holzapfel, W.H. The genus Carnobacterium. In The Genera of Lactic Acid Bacteria. The Lactic Acid Bacteria; Wood, B.J.B., Holzapfel, W.H., Eds.; Springer: Boston, MA, USA, 1995; Volume 2, pp. 307-326.

19. Gänzle, M.G. Lactic metabolism revisited: Metabolism of lactic acid bacteria in food fermentations and food spoilage. Curr. Opin. Food Sci. 2015, 2, 106-117. [CrossRef]

20. Ward, B. Bacterial energy metabolism. In Molecular Medical Microbiology, 2nd ed.; Tang, Y.W., Liu, D., Schwartzman, J., Sussman, M., Poxton, I., Eds.; Elsevier: Waltham, MA, USA, 2015; pp. 201-233.

21. Laursen, B.G.; Leisner, J.J.; Dalgaard, P. Carnobacterium Species: Effect of Metabolic Activity and Interaction with Brochothrix thermosphacta on Sensory Characteristics of Modified Atmosphere Packed Shrimp. J. Agric. Food Chem. 2006, 54, 3604-3611. [CrossRef]

22. Zhang, P.; Gänzle, M.; Yang, X. Complementary Antibacterial Effects of Bacteriocins and Organic Acids as Revealed by Comparative Analysis of Carnobacterium spp. from Meat. Appl. Environ. Microbiol. 2019, 85, e01227-19. [CrossRef] [PubMed]

23. Andersson, U.; Rådström, P. Beta-Glucose 1-phosphate-interconverting enzymes in maltose- and trehalose-fermenting lactic acid bacteria. Environ. Microbiol. 2002, 4, 81-88. [CrossRef]

24. Levisauskas, D.; Galvanauskas, V.; Henrich, S.; Wilhelm, K.; Volk, N.; Lübbert, A. Model-based optimization of viral capsid protein production in fed-batch culture of recombinant Escherichia coli. Bioprocess. Biosyst. Eng. 2003, 25, 255-262. [CrossRef]

25. Antelo, L.; Passot, S.; Fonseca, F.; Trelea, I.C.; Alonso, A.A. Towards optimal operation conditions of freeze-drying processes via a multi-level approach. Dry. Technol. 2012, 30, 1432-1448. [CrossRef]

26. Kiparissides, A.; Pistikopoulos, E.N.; Mantalaris, A. On the model-based optimization of secreting mammalian cell (GS-NS0) cultures. Biotechnol. Bioeng. 2015, 112, 536-548. [CrossRef] [PubMed]

27. Balsa-Canto, E.; Alonso, A.A.; Arias-Méndez, A.; Garcia, M.; López-Núñez, A.; Mosquera-Fernández, M.; Vázquez, C.; Vilas, C. Modeling and optimization techniques with applications in food processes, bio-processes and bio-systems. In Numerical Simulation in Physics and Engineering; Higueras, I., Roldán, T., Torrens, J., Eds.; Springer: Cham, Switzerland, 2016; Volume 9, pp. 187-216. 
28. Sanchez-Castaneda, A.; Athès, V.; Moussa, M.; Lopez-Miranda, J.; Paez-Lerma, J.; Soto-Cruz, N.; Trelea, I.-C. Modeling of isoamyl acetate production by fermentation with Pichia fermentans in an aerated system coupled to in situ extraction. Process. Biochem. 2018, 65, 11-20. [CrossRef]

29. Sinner, P.; Kager, J.; Daume, S.; Herwig, C. Model-based analysis and optimisation of a continuous Corynebacterium glutamicum Bioprocess Utilizing Lignocellulosic Waste. IFAC-Pap. 2019, 52, 181-186. [CrossRef]

30. Battley, E.H. Growth-Reaction Equations for Saccharomyces cerevisiae. Physiol. Plant. 1960, 13, 192-203. [CrossRef]

31. Bastin, G.; Dochain, D. On-Line Estimation and Adaptive Control of Bioreactors; Elsevier: Amsterdam, The Netherlands, 1990; pp. $1-82$.

32. Bailey, J.E. Mathematical modeling and analysis in biochemical engineering: Past accomplishments and future opportunities. Biotechnol. Prog. 1998, 14, 8-20. [CrossRef]

33. Monod, J. Recherches sur la Croissance des Cultures Bactériennes; Hermann \& Cie: Paris, France, 1942.

34. Levenspiel, O. The monod equation: A revisit and a generalization to product inhibition situations. Biotechnol. Bioeng. 1980, 22, 1671-1687. [CrossRef]

35. Baranyi, J.; Roberts, T.A. A dynamic approach to predicting bacterial growth in food. Int. J. Food Microbiol. 1994, 23, 277-294. [CrossRef]

36. Aiba, S.; Shoda, M. Reassessment of the product inhibition in alcohol fermentation. J. Ferment. Technol. 1969, 47, 790-803.

37. Claret, C.; Bories, A.; Soucaille, P. Inhibitory effect of dihydroxyacetone on Gluconobacter oxydans: Kinetic aspects and expression by mathematical equations. J. Ind. Microbiol. 1993, 11, 105-112. [CrossRef]

38. Monod, J. The growth of bacterial cultures. Annu. Rev. Microbiol. 1949, 3, 371-394. [CrossRef]

39. Baranyi, J. Comparison of Stochastic and Deterministic Concepts of Bacterial Lag. J. Theor. Biol. 1998, 192, 403-408. [CrossRef] [PubMed]

40. Rolfe, M.; Rice, C.; Lucchini, S.; Pin, C.; Thompson, A.; Cameron, A.; Alston, M.; Michael, F.; Stringer, M.; Betts, R.; et al. Lag Phase Is a Distinct Growth Phase that Prepares Bacteria for Exponential Growth and Involves Transient Metal Accumulation. J. Bacteriol. 2012, 194, 686-701. [CrossRef]

41. Bouville, M. Fermentation kinetics including product and substrate inhibitions plus biomass death: A mathematical analysis. Biotechnol. Lett. 2007, 29, 737-741. [CrossRef]

42. Seber, G.; Wild, C. Nonlinear Regression, 2nd ed.; Wiley: Hoboken, NJ, USA, 2003.

43. Owens, J.D.; Legan, J.D. Determination of the Monod substrate saturation constant for microbial growth. FEMS Microbiol. Rev. 1987, 3, 419-432. [CrossRef]

44. Brock, T.D.; Madigan, M.T. Biology of Microorganisms, 6th ed.; Prentice Hall: London, UK, 1991; p. 353.

45. Rodríguez, J.; Lema, J.M.; Kleerebezem, R. Energy-based models for environmental biotechnology. Trends Biotechnol. 2008, 26, 366-374. [CrossRef]

46. Bellgardt, K.H. Bioprocess Models. In Bioreaction Engineering: Modeling and Control; Schügerl, K., Bellgardt, K.H., Eds.; Springer: Berlin/Heidelberg, Germany, 2000; pp. 44-105.

47. González-Cabaleiro, R.; Lema, J.M.; Rodríguez, J. Metabolic Energy-Based Modelling Explains Product Yielding in Anaerobic Mixed Culture Fermentations. PLoS ONE 2015, 10, e0126739. [CrossRef] 